\title{
II. Der Kabinettsbeschluss von 1951: Provisorium oder endgültige Regelung?
}

\section{Geltungsbereich und Handlungsspielraum des Kabinettsbeschlusses}

Am 27. Juli 1950 befasste man sich in Bonn erstmalig auf Regierungsebene mit der Betreuung überlebender Opfer von Menschenversuchen. Nachdem der Wirtschafts- und Sozialrat der Vereinten Nationen bereits im Mai 1950 dieses Thema auf der Agenda hatte, ${ }^{1}$ machten die Unionsabgeordneten Richard Jaeger, Maria Diet7. und Franz-Josef Wuermeling die Bundesregierung darauf aufmerksam, dass sich eine größere Anzahl von Personen im Inund Ausland, die durch Humanexperimente gesundheitlich schwer geschädigt worden waren, vielfach in schwerer Not befinden. ${ }^{2}$ Angesichts der besonderen moralischen Verpflichtung erklärte sich Finanzminister Fritz Schäffer im Namen der Bundesregierung bereit, in besonderen Notfällen eine wirksame Hilfe zuteilwerden zu lassen und im Haushaltsplan einen Betrag in entsprechender Höhe einzusetzen. ${ }^{3}$

Zwar nahm die Weltöffentlichkeit die Erklärung der Bundesregierung wohlwollend auf. Es wurde jedoch übersehen, dass dies nicht ausreichte, allen Betroffenen die vorgesehene Überbrückungshilfe zu bewilligen, da die Gewährung einer Beihilfe das Vorliegen eines schlüssigen Anspruchs nach den Entschädigungsvorschriften der Länder zur Voraussetzung hatte. Schon eine oberflächliche Prüfung der beim Bundesfinanzministerium eingegangenen Anträge ergab, dass es sich bei den Antragstellern vorwiegend um Ausländer handelte, die keinen Wiedergutmachungsanspruch hatten, weil es ihnen entweder an der erforderlichen räumlichen Beziehung zu einem Land des Bundesgebiets fehlte (Territorialitätsprinzip) oder weil sie die Anmeldefristen versäumt hatten (Stichtage). ${ }^{4}$ Nach fünfmonatigen Ressortbesprechungen, die die Erweiterung des personellen Geltungsbereiches zum Ergebnis hatten, fasste die Bundesregierung am 26. Juli 1951 einen Kabinettsbeschluss, der noch am selben Tag vom Bundespresseamt bekannt gegeben wurde:

„Die Bundesregierung ist unter Berücksichtigung der vorliegenden moralischen Verpflichtung bereit, auch solchen, jetzt im Ausland lebenden, aus Gründen der Rasse, des Glaubens, der Weltanschauung oder der politischen Überzeugung verfolgten Opfern von Menschenversuchen, denen mangels der Wohnsitzvoraussetzung oder wegen Ablaufs der Anmeldefrist ein Wiedergutmachungsanspruch aufgrund der in den Ländern des Bundesgebiets geltenden Entschädigungsgesetze nicht zusteht, in besonderen Notfällen eine wirksame Hilfe zuteil werden zu lassen. Opfer von Menschenversuchen, denen aus anderen Gründen ein Wiedergutmachungsanspruch nicht zusteht, sollen von der Hilfe nicht ausge-

1 United Nations Economic and Social Council (ECOSOC), Report of the $4^{\text {th }}$ Session of the Commission on the Status of Women vom 8. bis 19.5.1959, BA, B 126/12361.

2 BT-Drucksachen, 1/1260, 27.7.1950.

3 BT-Drucksachen, 1/1332, 6.9.1950.

4 Berechtigt war, wer am 1.1.1947 seinen Wohnsitz oder gewöhnlichen Aufenthalt in einem Land der US-Zone hatte oder seither diesem Land als Flüchtling zugewiesen worden war, außerdem Verfolgte, die vor dem Stichtag ausgewandert waren, aber ihren letzten Wohnsitz in diesem Land hatten. Zum Territorialitätsprinzip in dex Entschädigungsgesetzgebung siehe Hockerts, Entschädigung, S. 19-26. 
schlossen sein, sofern ihnen unter gröblicher Mißachtung der Menschenrechte ein dauernder Gesundheitsschaden zugeführt worden ist. "

Dieser Kabinettsbeschluss beseitigte die einengenden territorialen und formalen Voraussetzungen. Unter humanitären Gesichtspunkten erschien es ferner folgerichtig, grundsätzlich keines der Opfer von Menschenversuchen aus dem Kreis der zu Betreuenden auszuschließen. Im zweiten Absatz sollte dementsprechend auch in anderen, durch das Entschädigungsrecht nicht gedeckten Fällen ein weiterer Raum für Ermessensentscheidungen gewährt werden. Tatsächlich dachte man hier an die Überlebenden von Menschenversuchen, die als Kriminelle oder als Widerstandskämpfer in Konzentrationslagern inhaftiert waren. Bei dieser Opfergruppe war ein Wiedergutmachungstatbestand im Sinne der geltenden Entschädigungsgesetze nicht gegeben, da keine Verfolgung aus Gründen der politischen Überzeugung, der Rasse, des Glaubens oder der Weltanschauung vorlag. ${ }^{6}$

Zwar setzte die Bundesregierung damit ein deutliches Zeichen für ihren Wiedergutmachungswillen, die erweiterte Regelung blieb jedoch in mehreren Punkten unbefriedigend. Als „wirksame Hilfe" waren einmalige Hilfszahlungen geplant, die vornehmlich zur Verbesserung des Gesundheitszustands und zur ärztlichen Behandlung der Opfer gewährt wurden. Es handelte sich um eine freiwillige Hilfszahlung, auf die der Antragsteller keinen Rechtsanspruch hatte. ${ }^{7}$ Die Unterstützung nach Fürsorgegesichtspunkten sollte zwar in „besonderen Notfällen“ erfolgen, eine genauere Abgrenzung zwischen einer „Notlage“ und einer „besonderen Notlage“ behielt sich das Bundesfinanzministerium jedoch vor. Tatsächlich war der Kabinettsbeschluss von 1951 mit einer Fülle unbestimmter Rechtsbegriffe versehen. Formulierungen wie „besonderer Notfall“, „wirksame Hilfe“ oder "gröbliche Mißachtung der Menschenrechte" waren interpretationsbedürftig und ließen gleichzeitig Spielraum für willkürliche Entscheidungen. Denn schließlich, so das Finanzressort an das Auswärtige Amt, könne es „nicht Sache der Bundesregierung sein, Wünsche zu erfüllen, die sich schon aus rein materiellen Gründen nicht realisieren lassen ". 8 In der Praxis war die Gewährung der Hilfe somit an Voraussetzungen gebunden, die den Kreis der Berechtigten erheblich einschränkten.

Der Tatbestand der schweren gesundheitlichen Schädigung aufgrund eines Humanexperiments in einem Konzentrationslager konnte zwar eindeutig bewiesen sein, falls der Antragsteller sich nicht in einer wirtschaftlichen Notlage befand, wurde er jedoch im Sinne des Kabinettsbeschlusses nicht rechtswirksam. Konnte der Antragsteller also nicht nachweisen, dass er besonders bedürftig war, stand ihm keine Hilfe zu. Verschiedene Verfolgtenorganisationen übten an dieser äußerst fragwürdigen Regelung scharfe Kritik. So verwahrte sich die französische Association Nationale des Anciennes Déportées et Internées de la Résistance (ADIR) in einem Schreiben an das Bundesfinanzministerium im Namen der Betroffenen entschieden gegen diese Form der Verteilung von Almosen. ${ }^{9}$ Zwar wollte die Bundesregierung „engherzige Entscheidungen vermeiden“ und in zweifelhaften Fällen zugunsten der

\footnotetext{
5 Meldung des BPA, Nr.651/51 vom 26.7.1951.

6 Nach Annahme des Bundesfinanzministeriums handelte es sich bei den Überlebenden aus dem Inland meist um „Kriminelle“, vgl. Entwurf und Begründung des Kabinettsbeschlusses, BMF, Schäffer, an BKA, 10.7. 1951, S. 29f., Bundesarchiv Koblenz (BA), B 136/1153.

7 BMF an AA, Tätigkeitsbericht vom 27.11.1957, BA, B 126/61084.

8 BMF an AA, 13.7. 1953, PA/AA, B 81/147.

9 "Il ne saurait être question d'une aumône du Gouvernement Allemand, mais de l'application d'une rigoureuse justice“, ADIR an BMF, 14.11.1955, BA, B 126/61084.
} 
Opfer urteilen - so die offizielle Verlautbarung. ${ }^{10}$ Tatsächlich sollte aber bei der Prüfung der wirtschaftlichen Notlage mit besonderer Sorgfalt vorgegangen werden, „um Zahlungen an Personen, die diese Voraussetzung nicht erfüllen, zu verhindern “. ${ }^{11}$

Dem Finanzministerium ging es in erster Linie darum, rechtlich einklagbare und dauerhafte Ansprüche unter allen Umständen zu vermeiden, da man ansonsten unkalkulierbare Kosten auf die Bundesrepublik zukommen sah. Hier spiegelt sich ein grundsätzlicher Konflikt wider, der sich durch die Geschichte der Wiedergutmachung zieht. So wurde von staatlicher Seite immer wieder versucht, Entschädigungszahlungen als Vorsorge oder Hilfe zu deklarieren, während sich die Verfolgten und ihre Anwälte dafür einsetzten, dass es sich um einen klaren Rechtsanspruch handele. Zwar spricht der Kabinettsbeschluss von der hier vorliegenden moralischen Verpflichtung, das Rechtsgefühl der Opfer wurde jedoch weitestgehend außer Acht gelassen. Denn gerade die Entscheidung, ob der Anspruch auf Wiedergutmachungsleistung „ex caritate“ oder „ex justitia“ bestehe, wäre für die Wiederherstellung des Rechtsempfindens der Betroffenen entscheidend gewesen.

Bei der Durchführung des Kabinettsbeschlusses handelte es sich um eine Sonderaktion, „die nur eine begrenzte Wirkung hat und haben sollte“. ${ }^{12}$ Beihilfen in Form von laufenden Unterhaltsrenten waren daher nicht vorgesehen, sondern nur einmalige Zahlungen zur Besserung der Gesundheit oder zur ärztlichen Behandlung. ${ }^{13}$ Auch im Verlauf der Aktion wurde an dieser Form des Härtefonds festgehalten, obwohl ausländische Verbände sowie die französische Regierung ${ }^{14}$ wiederholt eine Änderung der Verfahrensweise forderten. Im Jahr 1958 berichtete das Bundesfinanzministerium an das Bundeskanzleramt: „Seit Jahren bemühen sich die Association Nationale des Anciennes Déportées et Internées de la Résistance, Paris, [...] und die Friends of ADIR Inc., New York [...], in immer erneuten Eingaben, den im Ausland lebenden überlebenden Opfern von Menschenversuchen einen gesetzlichen Anspruch auf eine Unterhaltsrente zu verschaffen. "15. Und das Auswärtige Amt vermeldete in dieser Angelegenheit, dass sich „für diesen Wunsch, hinter dem französische Organisationen stehen, u.a. Mme. G. de Gaulle, eine Nichte des Präsidenten, die selbst in Ravensbrück war, nachdrücklich [einsetzt] “. ${ }^{16}$

Offiziell wurden verwaltungstechnische Schwierigkeiten als Ablehnungsgrund für die Gewährung laufender Beihilfen vorgeschoben. ${ }^{17}$ Aus regierungsinternen Schriftwechseln geht jedoch hervor, dass rechtliche und finanzielle Erwägungen ausschlaggebend waren. So äußerte das Bundesfinanzministerium intern die Befürchtung, dass mit der Zuerkennung von Rentenzahlungen ein gefährliches Präjudiz geschaffen werde. ${ }^{18}$ Angesichts der drohenden finanziellen Auswirkungen sollte unter keinen Umständen der Damm gegen die Rentenansprüche anderer Verfolgtengruppen durchlöchert werden. Im Erleben der Betroffenen machte es allerdings einen entscheidenden Unterschied, ob die Verfolgungsschäden mit einer einmaligen Sonderzahlung oder mit laufenden Leistungen anerkannt

${ }^{10}$ AA an Botschaft Paris, 15. 12. 1956, BA, B 126/61084.

11 Runderlass Nr. 101 des hessischen Ministers des Inneren vom 11.3.1952, betr. Zahlungen von Notstandsbeihilfen nach dem Gesetz über die Bildung eines Sonderfonds, BA, B 126/1251.

12 BMF an AA, 13.7. 1953, PA/AA, B 81/147.

13 Ebd.

14 Schuman an Adenauer, 24. 1. 1957, PA/AA, B 81/215.

15 BMF an BKA, 25.7. 1958, BA, B 126/61084.

16 AA an BKA, 28.9.1959, PA/AA, B 81/215.

$17 \mathrm{BMF}$ an ADIR, 10.3. 1958, BA, B 126/61084.

18 BMF an den Staatssekretär des BKA, 25.7.1958, BA, B 126/61084. 
wurden. Tobias Winstel kommt in einem neueren Forschungsbeitrag, der sich mit der Bedeutung von Wiedergutmachung aus der Opferperspektive befasst, zu dem Schluss, dass sich gerade „mit Blick auf Reconciliation und Rehabilitation“ erkennen lässt, „daß Wiedergutmachung auch eine Langzeitwirkung entfaltete - in der Erfahrung der Opfer ebenso wie im staatlichen Handeln". ${ }^{19}$

Mit dem Beschluss der Bundesregierung, eine Beihilfe zur Linderung bestehender Notlagen zu leisten, war keine Entschädigungszahlung nach Maßgabe des erlittenen und fortbestehenden Gesundheitsschadens verbunden. Aus der begrenzten Zweckbestimmung der Beihilfe für überlebende Opfer von Menschenversuchen ergab sich die strenge Subsidiarität der Leistungen aus dem Sonderfonds. Mit anderen Worten: Der einmalige Beitrag wurde im Fall von späteren Wiedergutmachungsleistungen angerechnet; umgekehrt wurde eine Beihilfe aus dem Sonderfonds verweigert, wenn dem Antragsteller ein anderweitiger Anspruch aufgrund der Entschädigungsgesetzgebung zustand. Erst ein Grundsatzurteil des Oberverwaltungsgerichtes Münster im Jahr 1974 nahm von dieser Regelung mit der Begründung Abstand, dass es sachlich nicht einleuchtend sei, das Prinzip der wirksamen Hilfe aufzugeben und den Betroffenen Leistungen aus dem Sonderfonds lediglich deshalb nicht zu gewähren, weil sie sonstige geringfügige Leistungen erhalten hätten. ${ }^{20}$

Die Fürsorge für überlebende Opfer von Menschenversuchen war 1951 als „Überbrückungsmaßnahme“ bis zu einer befriedigenden Regelung des Entschädigungsrechts deklariert und damit nur auf Härtefälle beschränkt. Da die Betroffenen auf die Verabschiedung des Bundesentschädigungsgesetzes vertröstet wurden, hatten ausländische Regierungen, Verfolgtenverbände und nicht zuletzt die Antragsteller die vermeintlich berechtigte Hoffnung, dass eine endgültige Regelung der Ansprüche geplant sei. ${ }^{21}$ Tatsächlich hielt das federführend mit der Wiedergutmachung betraute Finanzministerium eher aus taktischen Gründen daran fest, den Übergangscharakter des Kabinettsbeschlusses zu betonen, während in Regierungskreisen schon 1952 anders gesprochen wurde. „Ich halte es auch nicht für angezeigt, die Entschädigung für überlebende Opfer von Menschenversuchen grundsätzlich als ,vorläufige Maßnahme' zu bezeichnen, da diese Entschädigung [...] eine endgültige Regelung darstellt“, schrieb das Bundesjustizministerium an das Bundesfinanzministerium..$^{22}$ Entsprechend wurden die überlebenden Opfer von Menschenversuchen im ersten bundeseinheitlichen Entschädigungsgesetz von 1953 nicht berücksichtigt und auch in das Bundesentschädigungsgesetz (BEG) von 1956 sowie in das BundesentschädigungsSchlussgesetz (BEG-SchlG) von 1965 nicht einbezogen.

Etwa ein Drittel der Antragsteller war jedoch bis zum Jahr 1960 auch von den Leistungen aus dem Sonderfonds ausgeschlossen, da es sich um Betroffene aus osteuropäischen Ländern handelte. ${ }^{23}$ Obwohl man sich im Rahmen des Kabinettsbeschlusses bereit erklärt

19 Winstel, Bedeutung der Wiedergutmachung, S. 220; Winstel führt in dieser Untersuchung die drei Begriffe Reconciliation (Aussöhnung zwischen Tätergescllschaft und Opfer), Rehabilitation (Anerkennung von Leid und Eingestehen der Schuld) und Compensation (Wiedergutmachung) ein, um anhand dieser Kategorien die Erfahrungsgeschichte der Wiedergutmachung zu überprüfen.

20) Entscheidung des OVG Münster vom 10.6.1974, in: RzW 4 (1975), S. $126 \mathrm{f}$.

21 „Die niederländische Regierung hat jedoch Kenntnis davon genommen, daß die Auszahlungen [...] lediglich für besondere Notfälle vorgesehen sind und daher einen provisorischen Charakter tragen." Niederländisches Außenministerium Den Haag an AA, 7. 10. 1952, PA/AA, B 81/147.

22 BMJ an BMF, 15. 10.1951, PA/AA, Abt. II, Bd. 1663.

23 Aktenvermerk Biermanns, AA, vom 8.5.1952, über die erste Sitzung des Interministeriellen Ausschusses am 6.5.1952, PA/AA, B 10/1664. 
hatte, den überlebenden Opfern von Menschenversuchen ungeachtet ihres Wohnsitzes wirksam zu helfen, sollte Personen, die in Staaten lebten, mit denen die Bundesrepublik Deutschland keine diplomatischen Beziehungen unterhielt, keine Wiedergutmachung gewährt werden. Als Argument für diese Vorgehensweise hob man insbesondere verwaltungstechnische Schwierigkeiten hervor. Denn aufgrund des Fehlens diplomatischer Beziehungen sei eine einwandfreie Bearbeitung der Anträge nicht gewährleistet, da die notwendigen Ermittlungen über die Schadenstatbestände nicht durch deutsche Auslandsvertretungen getroffen werden könnten. ${ }^{24}$ Das Angebot der Vereinten Nationen, die Bundesregierung bei den Untersuchungen zu unterstützen oder zu diesem Zweck neutrale Organisationen einzuschalten, nahm das Bundesfinanzministerium gleichwohl nicht an. ${ }^{25}$

\section{Das bundesdeutsche Entschädigungsrecht und die Opfer von Menschenversuchen}

In dem am 26. Mai 1952 unterzeichneten Überleitungsvertrag mit den drei westlichen Besatzungsmächten hatte sich die Bundesregierung zu einer bundeseinheitlichen Regelung der Entschädigung verpflichtet. ${ }^{26}$ Am Ende der ersten Legislaturperiode des Deutschen Bundestags wurde das Bundesergänzungsgesetz (BergG) verabschiedet. Dieses erste bundeseinheitliche Entschädigungsgesetz, das dem Namen entsprechend lediglich Ergänzungen zu bestehenden länderbezogenen Regelungen vorsah, trat am 1.Oktober 1953 in Kraft. Schon zum Zeitpunkt der Verabschiedung war jedoch klar, dass es sich hier um eine „noch nicht ganz ausgereifte ,Frühgeburt “" ${ }^{\text {"27 }}$ handelte. Neben den Verfolgtenverbänden drängte auch die Alliierte Hohe Kommission auf Änderung des Gesetzes, vor allem im Hinblick auf eine Erweiterung des Kreises der Berechtigten und eine Erhöhung der Einzelleistungen.

Drei Jahre später, am 29.Juni 1956, wurde das „Bundesgesetz zur Entschädigung für Opfer nationalsozialistischer Verfolgung“, kurz Bundesentschädigungsgesetz (BEG), verabschiedet. Entsprechend der Auffassung des Bundesfinanzministeriums, das den Sonderfonds für Opfer von Menschenversuchen verwaltete, sollte die Gewährung von Entschädigung gemäß dem Kabinettsbeschluss schon nach Inkrafttreten des Bundesergänzungsgesetzes beendet werden..$^{28}$ Die Forderung der französischen Verfolgtenorganisation ADIR, eine gesetzliche Regelung zugunsten der Betroffenen im Rahmen der Novellierung dieses Gesetzes zu treffen, ${ }^{29}$ war bei den Beratungen nicht berücksichtigt worden. Verfolgte, die durch einen medizinischen Versuch in ihrer Erwerbsfähigkeit um mindestens 25 Prozent

24 Im Oktober 1958 gab Staatssekretär Alfred Hartmann, BMF, dies als Grund für die Zurückstellung der Anträge an, nachdem der SPD-Abgeordnete Willy Könen diese Regelung kritisiert hatte, vgl. Verhandlungen des Deutschen Bundestages. Stenographische Berichte (BT-Berichte), 46. Sitzung, 3. WT, 17.10.1958.

25 BMF an AA, 10.12. 1958, PA/AA, B 81/149.

${ }^{26}$ Zur Bundesentschädigungsgesetzgebung siehe auch Hockerts, Entschädigung, S. 19-26; einen Überblick über die Entschädigungsgeschichte gibt Hockerts, Wiedergutmachung. Ein umstrittener Begriff, S. 7-33; ausführlicher ist Goschler, Schuld und Schulden.

27 Heßdörfer, Entschädigungspraxis, S. 233.

28 Aufzeichnung einer Besprechung zwischen BMF und BMJ vom 12.5.1953, PA/AA, Abt.II, Bd.1663.

${ }^{29}$ ADIR an die Parlamentarische Arbeitsgruppe für die Vorbereitung des Bundesentschädigungsgesetzes, 14.11.1955, BA, B 126/61084. 
eingeschränkt waren, konnten zwar einen Schaden an Körper und Gesundheit gemäß Paragraf $28 \mathrm{ff}$ BEG geltend machen, allerdings nur dann, wenn sie aus Gründen der Rasse, des Glaubens, der Weltanschauung oder der politischen Überzeugung gemäß Paragraf 1 $\mathrm{BEG}$ verfolgt worden waren und die besonderen Anspruchsvoraussetzungen wie etwa den Wohnort (gemäß Paragraf 4 BEG) erfüllten.

Weiterhin war ein Großteil der überlebenden Opfer von Menschenversuchen nach dem neuen Gesetz nicht anspruchsberechtigt. Sie wurden erneut auf den Kabinettsbeschluss verwiesen, der die Gesetzeslücke schließen sollte. ${ }^{30}$ Gegenüber der Verfolgtenorganisation ADIR, die den einschränkenden Charakter der allgemeinen Vorschriften des Bundesentschädigungsgesetzes wiederholt kritisiert hatte, verwies das Bundesfinanzministerium stattdessen auf die Vorteile des Kabinettsbeschlusses, da man aufgrund dieser Sonderaktion an keine formellen Voraussetzungen gebunden sei und dementsprechend in einem unbürokratischen Verfahren nach den Grundsätzen der Billigkeit frei entscheiden könne. ${ }^{31}$

Daher hatte sich der im Bundesfinanzministerium für diese Angelegenheit verantwortliche Ministerialdirektor Bernhard Wolff in einem Schreiben an seinen Nachfolger Georg Blessin entschieden gegen eine weitere Novellierung des Entschädigungsgesetzes ausgesprochen und empfohlen, den „Zweifellos nicht ganz unberechtigten“ Forderungen der Betroffenen nach einer rechtlichen Regelung weiterhin auf der Grundlage des Kabinettsbeschlusses zu begegnen. ${ }^{32}$ Zudem schien aus rechtspolitischen Gründen die Berücksichtigung einer besonderen Gruppe von Geschädigten im Gesetz wegen der zu erwartenden Ansprüche anderer Verfolgtengruppen nicht opportun.

Entgegen den Erwartungen der Antragsteller und ihrer Interessenvertreter wurde der Kabinettsbeschluss somit nicht von einer günstigeren Regelung im Rahmen des Bundesentschädigungsgesetzes abgelöst. Nach Auffassung des Bundesfinanzministeriums war dies auch nicht mehr notwendig, da die Zuständigen bereits 1954 davon ausgingen, dass die Aktion in Kürze auslaufen werde. Eine zeitliche Begrenzung der Regelung von 1951 war somit hinfällig und in den Augen der Finanzbehörde „aus taktischen Gründen "33 nicht empfehlenswert. Denn nicht zuletzt spielte der Zeitfaktor in der Strategie der Entscheidungsträger eine wesentliche Rolle. Solange man den Ansprüchen der Antragsteller auf der Grundlage des Kabinettsbeschlusses begegnen konnte, war es möglich, eine gesetzliche Regelung zugunsten dieses Personenkreises zu umgehen. Auch als sich die Annahme, dass die Zahl der Anträge nach 1954 massiv abnehmen werde, als Fehleinschätzung herausstellte, hielt man an dem eingeschlagenen Kurs fest. In einem Schreiben des Auswärtigen Amts an die Botschaft der Bundesrepublik in Paris kam unmissverständlich zum Ausdruck, dass "die Bemühungen des A.D.I.R., aus den Unterstützungen eine Dauereinrichtung zu machen, $[. .$.$] - so verständlich sie sind - keine Aussicht auf Erfolg " hätten. { }^{34}$

Fast zehn Jahre nach Verabschiedung des Bundesentschädigungsgesetzes wäre es erneut möglich gewesen, die Opfer von Menschenversuchen als Verfolgte des NS-Regimes gesetzlich anzuerkennen und ihnen einen Rechtsanspruch auf Entschädigung zu gewähren, nachdem der beständige Kampf von verschiedenen Verfolgtenverbänden zu einer weiteren Novellierung geführt hatte. Im Mai 1965 wurde das Bundesentschädigungs-Schlussgesetz

30 Metz, Fürsorge, S. 293f.

31 BMF, Wolff, an ADIR, 20.3.1956, BA, B 126/61084.

32 Wolff an Blessin, 16.8.1956, BA, B 126/61084.

33 Aufzeichnung einer internen Besprechung im BMF vom 23.3. 1954, BA, B 126/12553.

34 AA an Botschaft Paris, 15.12. 1956, BA, B 126/61084. 
(BEG-SchlG) verabschiedet und im September desselben Jahres verkündet. ${ }^{35}$ Die Abgeordneten der Regierungskoalition hatten darauf bestanden, dass es entsprechend der Namensgebung ein Schlussgesetz sei. Doch erneut waren wesentliche Forderungen der Verfolgtenverbände nicht berücksichtigt worden. Zwar trugen neue Bestimmungen wie der Paragraf 31 BEG-SchlG unter dem Schlagwort „KZ-Vermutung“36 der Beweisnot der Antragsteller Rechnung, eine generelle Beweiserleichterung bei Körper- und Gesundheitsschäden wurde jedoch abgelehnt. Die in den Gesetzen festgelegten Fristen für die Anmeldung von Ansprüchen wurden ein weiteres Mal verlängert. Sie wurden jedoch nicht, wie gefordert, grundsätzlich gestrichen, da „Ausschlussfristen“ in Form von Stichtagen einen Abschluss der Entschädigungsleistungen garantieren sollten. Auch das Territorialitätsprinzip war weiterhin ausschlaggebend.

Wie schon im Bundesentschädigungsgesetz war in der Gesetzesnovelle von 1965 der Kreis der Anspruchsberechtigten begrenzt. Weder den Opfern von Menschenversuchen noch anderen bisher „vergessenen "Verfolgtengruppen gelang es, in die gesetzlichen Regelungen des Bundesentschädigungs-Schlussgesetzes miteinbezogen zu werden. Seit 1965 wurde an der Entschädigungsgesetzgebung - abgesehen von einigen zusätzlichen Härtefonds - grundsätzlich nichts geändert, da eine weitere Novellierung aus innenpolitischen Gründen unerwünscht war. Nicht etwa, weil es nichts zu verbessern gegeben hätte, wie der Präsident des Bayerischen Landesentschädigungsamts, Karl Heßdörfer, 1989 bemerkte, sondern aus Furcht vor den Konsequenzen, denn „die Exekutive hat geradezu ein ,Novellierungstrauma' entwickelt, sie zweifelt an der Fähigkeit der Legislative, ein Gesetz so zu ändern, dass es noch finanzierbar bleibt" ${ }^{37}$ Gegenüber den Betroffenen schien es jedoch angesichts der moralischen Verpflichtung der Bundesrepublik nicht angebracht, sich hinter finanzpolitischen Argumenten zu verstecken. Als Ursache für die Ablehnung von weiteren Novellierungsvorschlägen sollten daher „rechtssystematische Gründe“ genannt werden, die es nicht erlaubten, weitere Ansprüche zu eröffnen. ${ }^{38}$ Gesetzgeberische Prinzipien wie der Grundsatz der „Rechtssicherheit“ und die Ethik des Rechtsfriedens sollten unter allen Umständen gewahrt bleiben. ${ }^{39}$

Tatsächlich war ein voller, individualisierender Schadensersatz im Sinne des bürgerlichen Rechts angesichts des Massenunrechts aus finanziellen und auch aus organisatorischen Gründen nie vorgesehen. Auf dem Gebiet der Entschädigungsgesetzgebung waren sowohl die Anspruchsgrundlagen als auch die Leistungen Gegenstand von Pauschalisierung. Die Zahl der nachweisbaren Ausnahmen vom typischen Geschehen war jedoch so groß, dass sie sich in einem nennenswerten Prozentsatz von Fehlentscheidungen niederschlagen musste. So führte das Fehlen einer gesetzlichen Regelung zugunsten der Opfer von Menschenversuchen in der Entschädigungspraxis unweigerlich zu einer Ungleichbehandlung von gleichen Tatkomplexen.

Aufgrund der rechtlichen Unsicherheit war der verfassungsmäßig geforderte Gleichbehandlungsgrundsatz in vielen Fällen nicht mehr gewährleistet. Während nur für einen

35 Dazu Blessin/Giessler, Kommentar zum Bundesentschädigungs-Schlußgesetz; kritisch diskutiert sind die Bestimmungen des BEG-SchlG bei Pross, Wiedergutmachung, S. 110-129; Pawlita, Beitrag der Rechtssprechung zur Entschädigung; Goschler, Schuld und Schulden, S. 254-292.

${ }^{36}$ Bei einer KZ-Haft von mindestens einem Jahr wurde zugunsten des Inhaftierten ein Gesundheitsschaden vermutet.

37 Heßdörfer, Entschädigungspraxis, S. 239.

38 Blessin an Etzel, 25. 7. 1958, BA, B 126/61084.

39 Siehe dazu Fischer-Hübner, Geschichte der Entschädigungsmaßnahmen, S. 28f. 
Bruchteil der Antragsteller ein Anspruch auf Entschädigungsleistung wegen Schadens an Körper und Gesundheit gemäß der Wiedergutmachungsgesetzgebung bestand, kam für die meisten Betroffenen, wenn überhaupt, nur eine einmalige finanzielle Leistung aus dem durch den Kabinettsbeschluss geschaffenen Sonderfonds in Frage. Dass die Interessen der Antragsteller nicht einheitlich gewahrt werden konnten, ergab sich zudem aus der „diplomatischen Klausel“, die entscheidenden Einfluss auf den Beihilfeanspruch hatte: An die überlebenden Opfer von Menschenversuchen aus den osteuropäischen Staaten flossen bis zum Jahr 1960 keine Entschädigungsleistungen aus dem Sonderfonds.

Tatsächlich hatte der Gesetzgeber von Anfang an erklärt, es sei unmöglich, alles nationalsozialistische Unrecht zu entschädigen und eine vollständige Wiedergutmachung zu gewährleisten. ${ }^{40}$ So wird in der Entschädigungsdiskussion nach 1945 deutlich, dass nicht alle Verfolgten gleichermaßen anerkannt werden sollten, da die nur in begrenztem Umfang zur Verfügung gestellten Mittel unweigerlich den Handlungsspielraum vorgaben. Gleichzeitig wurde immer wieder betont, dass man die Wiedergutmachung als Ganzes sehen und demzufolge - bei aller Kritik - auch als bleibende deutsche Leistung anerkennen müsse. Vom Standpunkt des internationalen Rechts war die Rückerstattungs- und Wiedergutmachungsgesetzgebung zweifellos eine bahnbrechende Initiative, die ein neues Rechtsprinzip schuf. Es ist jedoch nicht zu übersehen, dass sie in vielen Fällen unvollkommen blieb und in allzu vielen Einzelfällen ungerechte und unverständliche Entscheidungen getroffen wurden.

Fragt man nach den Gründen für diese Defizite, dann muss man den experimentellen Charakter als Merkmal der Wiedergutmachung in Rechnung stellen. Tatsächlich war dem Gesetzgeber anfangs nur ein kleiner Teil der regelungsbedürftigen Tatbestände bekannt, da die gesamte Verfolgungswirklichkeit erst im Laufe der Jahre ans Licht kam. So betonte der deutsche Entschädigungsexperte Walter Schwarz, dass man sich mit der Wiedergutmachung auf rechtlichem Neuland bewegt habe und aus diesem Grund jede gesetzliche Regelung nur ein Versuch habe sein können. ${ }^{41}$ Gleichzeitig versäumte er jedoch nicht, darauf hinzuweisen, dass die Wiedergutmachung niemals populär gewesen sei: „Die Wiedergutmachung hat sich in der Tat unter Ausschluß der Öffentlichkeit, in einem politischen Ghetto abgespielt. Warum das so war, kann nur vermutet werden. Die ,Bewältigung' der Vergangenheit ist ein beliebtes Schlagwort, aber konkret nur in kleinsten Ansätzen [...] verwirklicht worden. Von der Wiedergutmachung des im Namen des deutschen Volkes angetanen Unrechts, also von einem echten Akt der Sühne, möchte niemand gerne etwas wissen." 42

Das Scheitern vor der moralischen Verantwortung und die restriktive finanzpolitische Haltung behinderten die Entfaltung der potenziellen legislativen Möglichkeiten. Nur widerwillig erinnerte man sich, dass die Wiedergutmachung nationalsozialistischen Unrechts nach 1945 eine der dringlichsten Aufgaben des neuen Staates war - nicht nur um sich in der Welt zu rehabilitieren, sondern auch um rechtswidrig Verfolgten wieder ihr Recht zu geben und auf diese Weise die Schulden aus der Schuld zu übernehmen.

40 Bericht der Bundesregierung über Wiedergutmachung und Entschädigung für nationalsozialistisches Unrecht sowie über die Lage der Sinti, Roma und verwandter Gruppen, BT-Drucksachen, 10/6287, 31. 10. 1986.

41 Schwar, Wiedergutmachung des nationalsozialistischen Unrechts, S. 237.

42 Ebd., S. 227. 


\section{Der Kabinettsbeschluss in der bürokratischen Umsetzung}

Für die Umsetzung des Kabinettsbeschlusses wurde ein Interministerieller Ausschuss gebildet, dem Vertreter des Auswärtigen Amts, des Bundesinnenministeriums, des Bundesjustizministeriums sowie medizinische Sachverständige des Bundesministeriums für Arbeit und Sozialordnung, seit 1961 auch des Bundesministeriums für Gesundheitswesen angehörten. Unter dem Vorsitz des Bundesfinanzministeriums, das federführend mit der Betreuung der Opfer von Menschenversuchen befasst war, entschied das Gremium über die Bewilligung von Beihilfen. Eine gutachterliche Stellungnahme zu jedem Antrag wurde vom Bundesfinanzministerium und, soweit erforderlich, von den einzelnen Ministerien vorbereitet; die Entschließung zu Gunsten oder Ungunsten eines Antragstellers erfolgte letztlich in einer gemeinsamen Sitzung des Interministeriellen Ausschusses, der im Mai 1952 erstmalig tagte. Der Ausschuss trat etwa vierteljährlich zusammen und behandelte in jeder Sitzung durchschnittlich 20 Fälle.

Da die einzelnen Anträge hinsichtlich ihrer besonderen Umstände beurteilt werden sollten, war es Aufgabe des Ausschusses, die Höhe der Beihilfen der Verschiedenartigkeit der gesundheitlichen Folgen anzupassen. Die Antragsteller, denen eine Fürsorgeleistung zuerkannt wurde, erhielten je nach Art und Auswirkungen des Versuchs und unter Berücksichtigung ihrer wirtschaftlichen Situation Beträge zwischen 2000 und 25000 Mark unter dem Vorbehalt der Anrechnung auf Entschädigung für Schaden an Körper und Gesundheit nach dem Bundesentschädigungsgesetz. ${ }^{43}$ Die Auszahlung des veranschlagten Betrages an den Antragsteller erfolgte in der betreffenden Landeswährung durch das jeweilig zuständige deutsche Generalkonsulat. ${ }^{44}$ Für die Betreuung des Personenkreises wurden in den Rechnungsjahren 1951 bis 1960 Haushaltsmittel in Höhe von insgesamt 3,7 Millionen Mark bewilligt, die jedoch nicht voliständig ausgeschöpft wurden. ${ }^{45}$

Diejenigen Anträge, die nicht den Voraussetzungen der Härteregelung von 1951 entsprachen, wurden abschlägig beschieden. Die Gründe, warum Anträge abgelehnt wurden, waren vielfältig. In den meisten Fällen konnte nicht eindeutig festgestellt werden, dass es sich um einen Menschenversuch im Sinne des Kabinettsbeschlusses gehandelt hatte; bei anderen Antragstellern lag entweder keine Notlage vor, oder es konnte kein dauernder Gesundheitsschaden aufgrund des Experiments nachgewiesen werden. Antragsteller, die einen Anspruch wegen Schaden an Körper und Gesundheit nach dem Bundesentschädigungsgesetz geltend machen konnten oder die eine vertrauensärztliche Untersuchung verweigerten, schieden als Berechtigte prinzipiell aus. Grundsätzlich bestand jedoch die Möglichkeit, Beschwerde gegen Beschlüsse des Interministeriellen Ausschusses einzulegen. Bei den Entscheidungen des Gremiums handelte es sich um Verwaltungsakte, gegen die Klage vor dem Verwaltungsgericht wegen Ermessensmissbrauchs eingereicht werden konnte.

Erst ein Jahr nach dem Erlass des Kabinettsbeschlusses begann die Durchführung unter grober Fehleinschätzung der Zahl der Opfer. Angesichts der etwa 250 bis zum Januar 1952 vorliegenden Anträge vertrat das Bundesfinanzministerium in einem Schreiben an das Bundeskanzleramt die Ansicht, dass nahezu alle in Frage kommenden Personen ihre Ent-

43 BMF an AA, Tätigkeitsbericht über die Durchführung des Kabinettsbeschlusses vom 27.11.1957, BA, B 126/61084.

44 BMF, Abt. VI an Abt. V, 9.4. 1952, BA, B 126/12554.

45 BMF, Blessin an Abt. I, betr. Haushaltsvoranschlag für das Rechnungsjahr 1960, 29.6. 1969, BA, B 126/61084. 
schädigungsansprüche bereits angemeldet hätten. ${ }^{46}$ Ein Grund für diese Fehleinschätzung war die Annahme, dass ohnehin nur diejenigen Betroffenen überlebt hätten, an denen "harmlose“ Experimente durchgeführt worden waren, da „Versuchspersonen, mit denen lebensgefährliche Experimente vorgenommen wurden, [...] in der Regel ad exitum gekommen sind “ ${ }^{47}$ Zum anderen konnte - oder wollte - man sich offenbar gar keine Vorstellung über das wirkliche Ausmaß der Verbrechen machen.

Die Tatsache, dass es sich um eine weit größere Zahl von potenziellen Antragstellern handeln musste, die nicht Opfer von lebensgefährlichen Menschenversuchen geworden waren und folglich als Überlebende einen Antrag auf Entschädigung stellten, wurde auf fatale Weise ignoriert. Da die Zahl der eingehenden Anträge dann weitaus größer als erwartet war - im Mai 1960 weist die Statistik insgesamt 1740 eingegangene Anträge aus ${ }^{48}$-, versuchte das Bundesfinanzministerium, im weiteren Verlauf der Aktion die Zahl der Anspruchsberechtigten durch eine restriktive Handhabung des Kabinettsbeschlusses drastisch zu vermindern.

Tab. 1 Übersicht über die bis zum 1.10.1955 abschließend behandelten Anträge auf Fürsorge für überlebende Opfer von Menschenversuchen nach dem Kabinettsbeschluss vom 26.7.1951 ${ }^{49}$

\begin{tabular}{lrrrrrrrrr} 
& \multicolumn{1}{c}{} & \multicolumn{4}{c}{ Genehmigungen } & \multicolumn{3}{c}{ Ablehnungen } \\
Angegebene Versuche & \multicolumn{1}{c}{} & \multicolumn{1}{c}{$\boldsymbol{c}$} & $\Sigma$ & $\delta$ & $\uparrow$ & $\Sigma$ & $\delta$ & $q$ & $\Sigma$ \\
\hline Meerwasserversuche & 2 & - & 2 & - & - & - & 2 & - & 2 \\
Sterilisationsversuche & 62 & 283 & 345 & 52 & 242 & 294 & 10 & 41 & 51 \\
Fleckfieberversuche & 16 & 1 & 17 & 10 & 1 & 11 & 6 & - & 6 \\
Höhenversuche & 3 & - & 3 & 1 & - & 1 & 2 & - & 2 \\
Kälteversuche & 13 & - & 13 & 8 & - & 8 & 5 & - & 5 \\
Malariaversuche & 81 & 1 & 82 & 56 & - & 56 & 25 & 1 & 26 \\
Versuche betr. Knochen & 3 & 6 & 9 & 1 & 5 & 6 & 2 & 1 & 3 \\
und Muskelregeneration & & & & & & & & & \\
Phlegmoneversuche & 14 & - & 14 & 10 & - & 10 & 4 & - & 4 \\
Sonstige Versuche & 127 & 95 & 222 & 6 & 4 & 10 & 121 & 91 & 212 \\
\hline & 321 & 386 & 707 & 144 & 252 & 396 & 177 & 134 & 311
\end{tabular}

Dementsprechend oft wurde seitens der Interessenvertreter der Verfolgten beklagt, dass die Federführung in den Händen des Bundesfinanzministeriums lag, von dem man mit Recht Sparsamkeit als oberste Pflicht erwarten konnte. Hatte sich das Bundesfinanzministerium bereits in der innenpolitischen Diskussion um eine kommende Entschädigungsgesetzgebung als stärkster Verbündeter der Wiedergutmachungsgegner erwiesen, so war der Geist des Hauses auch in der Entschädigungspraxis unverkennbar. Wiedergutmachungsleistungen an NS-Verfolgte wurden vom Bundesfinanzministerium oft nur widerstrebend gewährt und hatten gegenüber anderen Haushaltstiteln, etwa der Versorgung der Kriegsopfer, nur sekundären Stellenwert.

\footnotetext{
46 BMF an BKA, 31.1.1952, BA, B 136/1153.

47 BMF, Schmidt, an Generalkonsulat Montreal, Dr. Adolph Reifferscheidt, 3.6. 1953, PA/AA, B 81/147.

48 Siehe dazu die Übersicht „Fürsorge für überlebende Opfer von Menschenversuchen. Stand: 10.5.1960“, BA, B 126/61084.

$49 \mathrm{BMF}$ an AA, Oktober 1955, BA, B 126/12554.
} 
Die mit der Durchführung der Wiedergutmachung betrauten Entschädigungsbehörden bewegten sich in einem engen Spielraum, da sie durch den Bundesrechnungshof kontrolliert wurden. Sollte sich also ein Beamter entschließen, die Paragrafen des Wiedergutmachungsgesetzes gegebenenfalls zugunsten des Antragstellers großzügiger auszulegen, konnte dies vom zuständigen Rechnungshof sofort unterbunden werden..$^{50}$ Auch die Wiedergutmachung für Opfer von Menschenversuchen war eindeutig von diesem Ressortdenken überschattet. Ohne Zwischenschaltung einer Entschädigungsbehörde fungierte der Interministerielle Ausschuss unter Vorsitz des Bundesfinanzministeriums als alleiniger Entscheidungsträger; gewissermaßen lagen Jurisdiktion und Exekutive in einer Hand. Die in diesem Zusammenhang von der Französischen Botschaft in einer Verbalnote geäußerte Kritik war entsprechend eindeutig: Die Behandlung der Anträge von Opfern medizinischer Versuche lasse oft die gebotene Großzügigkeit vermissen, da das Bundesfinanzministerium gleichzeitig „Richter" und „zahlende Partei“ sei. ${ }^{51}$

Tatsächlich entsprachen die ausbezahlten Leistungen in vielen Fällen nicht den in einem offiziellen Tätigkeitsbericht der Behörde angegebenen Entschädigungssätzen und häuften sich im Bereich der untersten Sätze. Veranschlagt waren für Sterilisationen 2000 bis 5000 DM, für Kastrationen 12000 bis 20000 DM, für schwere Phlegmoneexperimente sowie für Muskel- und Knochentransplantationen 20000 bis 25000 DM, für Fleckfieberversuche 2000 bis $10000 \mathrm{DM}$, für Höhenversuche 6000 bis $8000 \mathrm{DM}$, für Hormonversuche $4000 \mathrm{DM}$ und für Kälteversuche 3000 bis 15000 DM..$^{52}$

Tab. 2 Offizielle Entschädigungssätze ${ }^{53}$

Offizielle Entschädigungssätze für

Sterilisationen

Kastrationen

Schwere Phlegmoneexperimente

Muskel- und Knochentransplantationen

Fleckfieberversuche

Höhenversuche

Hormonversuche

Kälteversuche

\begin{tabular}{rr}
\multicolumn{1}{l}{ von } & \multicolumn{1}{l}{ bis } \\
$2000 \mathrm{DM}$ & $5000 \mathrm{DM}$ \\
$12000 \mathrm{DM}$ & $20000 \mathrm{DM}$ \\
$20000 \mathrm{DM}$ & $25000 \mathrm{DM}$ \\
$20000 \mathrm{DM}$ & $25000 \mathrm{DM}$ \\
$2000 \mathrm{DM}$ & $10000 \mathrm{DM}$ \\
$6000 \mathrm{DM}$ & $8000 \mathrm{DM}$ \\
-- & $4000 \mathrm{DM}$ \\
$3000 \mathrm{DM}$ & $15000 \mathrm{DM}$
\end{tabular}

Die Durchschnittsleistung je Einzelfall lag bei einer einmaligen Zahlung von knapp 6000 DM. ${ }^{54}$ Die Analyse einer internen Statistik des Bundesfinanzministeriums verdeutlicht, wie dieser angesichts des meist schweren Verfolgungsschicksals relativ niedrige Betrag zustande kam: ${ }^{55}$ Von 151 eingereichten Anträgen wurde etwa ein Drittel abgelehnt, und bei den positiv entschiedenen Fällen bewegten sich die Beträge deutlich im untersten Bereich

50 Zur Problematik der Kontrolle durch den Bundesrechnungshof und durch die Landesrechnungshöfe siehe Rothe, „Schleppende“ Arbeit, S. 359.

51 „[...] les critiques qui résultent du fait que le Ministère fédéral des Finances est en l'affaire à la fois juge et partie payant." Verbalnote der Französischen Botschaft in Bonn an AA vom 11.7. 1955, BA, B $126 / 12554$.

52 BMF an AA, Tätigkeitsbericht vom 27.11.1957, BA, B 126/61084.

53 BMF an AA, Tätigkeitsbericht vom 27.11.1957, BA, B 126/61084.

54 Ebd.

55 Tabellarische Liste über Entscheidungen und Auszahlungen bei 151 Antragstellern, BMF, o. D., BA, B $126 / 61084$. 
der möglichen Entschädigungsleistungen; in nur vier von hundert Fällen erfolgte eine Auszahlung über 10000 DM. So betrugen beispielsweise die Zahlungen bei Sterilisationsexperimenten durchschnittlich nur $2000 \mathrm{DM}$.

Aufschlussreich ist der Fall einer Antragstellerin, die seit 1945 infolge der Clauberg-Versuche in einem Amsterdamer Krankenhaus liegen musste. Die Frau, die - laut ärztlicher Prognose - das Krankenhaus aufgrund der schweren Folgeschäden niemals wieder verlassen konnte, erhielt eine einmalige Entschädigung von $2000 \mathrm{DM} .^{56}$ Bei den auf das Schwerste geschädigten Opfern von Phlegmoneversuchen kamen statt der zwischen 20000 und $25000 \mathrm{DM}$ veranschlagten Entschädigungsleistungen, wenn überhaupt, nur $5000 \mathrm{DM}$ zur Auszahlung. Von sechs Fällen wurden vier sogar abgelehnt, da nach Ansicht des Bundesfinanzministeriums entweder keine Notlage oder kein Menschenversuch vorlag. ${ }^{57}$

Für die Vermutung, dass auch in vielen anderen Fällen unter dem Primat der Sparsamkeit entschieden wurde, spricht die folgende Tatsache: Die in den Rechnungsjahren 1951 bis 1960 insgesamt bereitgestellten Haushaltsmittel in Höhe von knapp vier Millionen Mark für die Betreuung des betroffenen Personenkreises wurden nicht ausgeschöpft. ${ }^{58}$ Allein im Rechnungsjahr 1957 ergab sich ein Rest von rund $400000 \mathrm{DM} .{ }^{59}$ Zwar ist in einem in der Rechtsprechung zur Wiedergutmachung erschienenen Artikel über die „Fürsorge für überlebende Opfer von Menschenversuchen"von 14,5 Millionen DM die Rede, die die Bundesregierung für die Betroffenen bis zum Jahre 1963 gezahlt habe - wie sich diese dem Anschein nach generöse Summe jedoch zusammensetzt, ist nicht erwähnt. ${ }^{60}$

In der Öffentlichkeit wurde gerade von amtlicher Seite auf die statistisch ermittelten Wiedergutmachungskosten Bezug genommen, die in ihrer kolossal wirkenden Höhe die großzügige Entschädigungsbereitschaft der Bundesrepublik Deutschland beweisen sollten. In einem Bericht aus dem Jahr 1986 bilanzierte die Bundesregierung unter anderem die Entschädigungsleistungen des Bundes außerhalb des BEG. Die Gesamtaufwendungen für individuelle und globale Leistungen zugunsten der Opfer von medizinischen Versuchen aufgrund der Härteregelung betrugen demnach 183632663 DM. ${ }^{61}$ Davon entfielen auf Bewilligungen durch den Bundesminister der Finanzen allerdings nur 2,915 Millionen DM, während das Internationale Rote Kreuz ab 1960 für Betroffene aus osteuropäischen Staaten 53,375 Millionen DM zuzüglich der Verwaltungskosten in Höhe von 2,5 Millionen DM bewilligte. Zur Erfüllung von Globalabkommen mit vier osteuropäischen Staaten wurden 121 Millionen DM zuzüglich Verwaltungskosten von 3 Millionen DM aufgebracht. ${ }^{62}$ Mit

${ }^{56}$ Summary of the Situation of Victims of So-called Scientific Experiments, 1960, Caroline Ferriday Collection (CFC), United States Holocaust Memorial Museum Archives, Washington D. C. (USHMM), RG-10.204.03*05.

57 Ebd.

58 Haushaltsvoranschlag für das Rechnungsjahr 1960, BMF, Ref. V an Ref. I, 29.6.1959, BA, B 126/61084.

59 „Rechnungsjahr 1958: In diesem Rechnungsjahre stehen, vorbehaltlich der Genehmigung zur Übertragung des Ausgaberestes aus 1957 nach 1958, 607476 DM zur Verfügung. (Haushaltsansatz. 1958 = 200000 DM, Ausgaberest 1957 = 407476 DM) “, Tätigkeitsbericht des BMF, Stichtag 1.5.1958, BA, B 126/61084.

60 Metz, Fürsorge, S. 297.

6) Bericht der Bundesregierung über Wiedergutmachung und Entschädigung für nationalsozialistisches Unrecht sowie über die Lage der Sinti, Roma und verwandter Gruppen, BT-Drucksachen, 10/6287, 31.10.1986, S.18f. Die vergleichsweise hohe Summe von 183 Mio. DM entstand, weil aufgrund eines Kabinettsbeschlusses von 1960 Beihilfen auch an Opfer von Menschenversuchen gewährt wurden, die in Staaten lebten, mit denen die Bundesrepublik Deutschland keine diplomatischen Beziehungen unterhielt.

62 Vgl. Kapitel IV. in diesem Buch. 
Stand vom 1.September 1986 hatte der Interministerielle Ausschuss über 1147 Anträge von Verfolgten, die in westeuropäischen Staaten lebten, entschieden und davon 520 Härtebeihilfen bewilligt. Im Fall der Antragsteller aus den osteuropäischen Staaten wurden von 2266 Anträgen - nicht zuletzt aufgrund der Intervention des Internationalen Roten Kreuzes -1790 positiv entschieden. ${ }^{63}$

Den Verfolgten kamen also nicht die gesamten für die Wiedergutmachung entstandenen finanziellen Aufwendungen zugute. In Wahrheit entsprachen die genannten Summen nicht den tatsächlichen Entschädigungsleistungen, da der gesamte bürokratische Apparat, Gutachterhonorare und nicht zuletzt auch eine ganze Reihe von Rechtsstreitigkeiten einen hohen Kostenfaktor darstellten. Oft war es sogar die wiedergutmachungspflichtige Instanz - in diesem Fall das Bundesfinanzministerium -, die lieber ein Gerichtsverfahren anstrengte als freiwillig den Forderungen nachzukommen. Damit wurden Entscheidungen nicht selten über Jahre hinausgezögert, öffentliche Gelder nutzlos vertan und riskiert, dass der so mühsam geschaffene moralische Kredit der Bundesrepublik im Ausland in Frage gestellt wurde.

Da viele Verfolgte selbst oft nach jahrelangem Kampf nicht erleben konnten, dass ihnen Gerechtigkeit zuteilwurde, musste sich das Bundesfinanzministerium den Vorwurf gefallen lassen, im „Trauerspiel der Wiedergutmachung“ die Rolle des streitbaren Fiskus übernommen zu haben. ${ }^{64}$

\section{Die Interaktion zwischen Bundesfinanzministerium, Auswärtigem Amt und diplomatischen Vertretungen}

Als sich die Bundesregierung im Jahr 1951 bereit erklärte, den überlebenden Opfern von Menschenversuchen im Rahmen des Kabinettsbeschlusses schnelle und wirksame Hilfe zu gewähren, war bereits bekannt, dass sich ein Großteil der Antragsteller im Ausland befand. Sowohl die Bewilligung als auch die Höhe einer Entschädigungsleistung sollte sich demzufolge nicht nur an der Art und Schwere des Versuchs und dem daraus resultierenden Gesundheitsschaden orientieren. Der Interministerielle Ausschuss berücksichtigte bei den Entscheidungen ebenso die wirtschaftliche Lage und die soziale Stellung der Antragsteller sowie die Verschiedenartigkeit der Lebensverhältnisse in den einzelnen Aufenthaltsländern.

Nach Ansicht des Bundesfinanzministeriums erforderte die Durchführung des Kabinettsbeschlusses daher ,eine sorgfältige Ermittlungsarbeit an Ort und Stelle durch deutsche Behörden, um eine mißbräuchliche Anwendung auszuschließen “, da nicht alle erforderlichen Angaben der im Ausland lebenden Antragsteller nachgeprüft werden konnten. ${ }^{65}$ Auch die Bescheinigungen ausländischer Behörden und ärztlicher Gutachter wurden ohne die Möglichkeit einer Überprüfung seitens deutscher Dienststellen nicht anerkannt. Anhand der vom Internationalen Suchdienst Arolsen geführten Datei ${ }^{66}$ konnten Tatsache

$63 \mathrm{Vgl}$. Anm. 61.

64 Sagittarius, Streitbarer Fiskus.

65 BMF an BMJ, 5.2. 1953, PA/AA, B 81/147.

66 Die Hauptaufgabe des Internationalen Suchdienstes in der hessischen Stadt Bad Arolsen ist die Sammlung, Ordnung und Auswertung von Unterlagen über zivilc Opfer des Nationalsozialismus auf dem Gebiet des damaligen Deutschen Reiches sowie in den durch Deutschland besetzten Gebieten, deren Schicksal und Verbleib aufgrund von Deportation, Internierung, Vertreibung oder anderen mit dem Zweiten Weltkrieg im Zusammenhang stehenden Gründen ungeklärt ist. 
und Dauer der Konzentrationslagerhaft kontrolliert werden, allerdings nur in den Fällen, die bereits dokumentiert waren. Die Frage, ob im jeweiligen Fall eine besondere Notlage gegeben war und worin die wirksame Hilfe zu bestehen hatte, konnte wiederum nur vor Ort geklärt werden.

Die im Ausland ansässigen Betroffenen reichten die Anträge auf Entschädigung für überlebende Opfer von Menschenversuchen bei den jeweils zuständigen diplomatischen Vertretungen der Bundesrepublik Deutschland ein. Aufgabe der deutschen Gesandtschaften war es nunmehr, jeden einzelnen Fall vorab zu prüfen und gegebenenfalls die erforderlichen Ermittlungen anzustellen. Ferner waren sie angewiesen, über die Zahl der eingegangenen Anträge regelmäßig Bericht zu erstatten und die für eine Rückfrage in Arolsen wichtigen Angaben wie Name, Geburtsdatum, Häftlingsnummer, Lageraufenthalt sowie eine kurze Schilderung des vorgenommenen Versuchs dem Auswärtigen Amt in Bonn zu übermitteln. ${ }^{67}$

Von dort wurden die Unterlagen an das Bundesfinanzministerium weitergeleitet, das den Fall überprüfte und weitere Schritte für eine nächste Bearbeitungsphase anordnete. Hinsichtlich der Verfahrensweise waren die Auslandsvertretungen an die vom Bundesfinanzministerium erlassenen Direktiven gebunden. In Runderlassen wurden die entsprechenden Richtlinien für die Wiedergutmachungspraxis bei überlebenden Opfern von Menschenversuchen allen diplomatischen und berufskonsularischen Vertretungen der Bundesrepublik Deutschland bekannt gegeben, wobei dem Auswärtigen Amt die Rolle des Vermittlers zukam. ${ }^{68}$

So begann das eigentliche Nachprüfverfahren erst, wenn aufgrund einer eingehenden Vorprüfung mit großer Wahrscheinlichkeit anzunehmen war, dass ein Antragsteller zu dem Kreis der berechtigten Personen gehörte. Gemäß Kabinettsbeschluss war nur für „besondere Notfälle" eine Entschädigungsleistung vorgesehen. Die deutschen Auslandsvertretungen waren daher angehalten, zu der Frage, ob im Einzelfall eine besondere Notlage gegeben war, einwandfrei Stellung zu nehmen und ihre Ansicht unter Darlegung aller dafür und dagegen sprechenden Gründe zu vertreten. Nach Auffassung des Bundesfinanzministeriums war es in diesem Zusammenhang unerlässlich, die wirtschaftlichen und sozialen Verhältnisse jedes Antragstellers unter Berücksichtigung der Lebensverhältnisse im jeweiligen Land detailliert nachzuweisen. ${ }^{69}$ Darunter fielen Angaben über Art und Stetigkeit des Arbeitsverhältnisses, über die Höhe des Einkommens sowie gegebenenfalls Informationen über das Einkommen des Ehepartners; Zahl und Alter der im Haushalt des Antragstellers lebenden Kinder, deren etwaige Berufsbetätigung beziehungsweise Einkünfte waren ebenfalls anzugeben.

Ferner mussten die Auslandsvertretungen Auskünfte über Leumund und Bedürftigkeit der Antragsteller einholen ${ }^{70}$ und für eine ordnungsgemäße Beantwortung des Fragebogens sowie eine Nachprüfung der darin enthaltenen Angaben unter Erschöpfung aller zugänglichen Beweismittel Sorge tragen. ${ }^{71} \mathrm{Zu}$ diesem Zweck waren unter anderem auch die vom Antragsteller namhaft gemachten Zeugen ausfindig zu machen und zu befragen. ${ }^{72}$

67 BMF an AA, 11.2. 1953, BA, B 126/12553.

68 Runderlass an alle diplomatischen und berufskonsularischen Vertretungen der Bundesrepublik Deutschland.

69 BMF an AA, 2.8.1952, PA/AA, B 81/147.

70 BMF an AA, 13.3. 1952, BA, B 126/12554; Runderlass vom 7.4. 1952, BA, B 126/12553.

71 Runderlass vom 12.10.1951, BA, B 126/12553.

72 Runderlass vom 5. 2. 1952, PA/AA, Abt. II, Bd. 1664. 
„Zur Vermeidung unnötiger Kosten“ sollte eine vertrauensärztliche Untersuchung des Antragstellers von der deutschen Gesandtschaft erst dann veranlasst werden, wenn alle übrigen Voraussetzungen für die Gewährung einer Fürsorge erfüllt waren. ${ }^{73}$ Wurde die wirtschaftliche Lage eines Antragstellers als „gesichert" eingestuft, war von einer vertrauensärztlichen Untersuchung grundsätzlich abzusehen. ${ }^{74}$ Der gesundheitliche Schaden war also keineswegs der ausschlaggebende Faktor für eine Wiedergutmachungsleistung, sondern allenfalls eine von mehreren notwendigen Anspruchsvoraussetzungen.

Im Anschluss an diese umfangreichen Ermittlungen wurden die Antragsformulare mit den erforderlichen Unterlagen und den vertrauensärztlichen Gutachten nach Bonn geschickt, wobei das Bundesfinanzministerium eine ausführliche Stellungnahme zur Glaubwürdigkeit jedes Antragstellers erwartete. ${ }^{75}$ Das Auswärtige Amt leitete die gesamten Vorgänge wiederum an das Bundesfinanzministerium weiter, wo schließlich der Interministerielle Ausschuss die endgültige Entscheidung über die Anspruchsberechtigung sowie die Höhe der Entschädigungsleistung traf. Die deutschen Auslandsvertretungen übernahmen dann wiederum die Auszahlung der Beträge in der jeweiligen Landeswährung an die Antragsteller, die von Bonn einen positiven Bescheid erhalten hatten. Diese Verfahrensweise erschien dem Bundesfinanzministerium nicht zuletzt aus außenpolitischen Gründen opportun, um „das Vertrauen zu den deutschen Auslandsvertretungen gerade in diesen Kreisen und von der an ihrem Schicksal interessierten Öffentlichkeit im Auslande wesentlich zu unterstützen " ${ }^{76}$

Die Durchführung der erforderlichen Ermittlungen erwies sich jedoch aus verschiedenen Gründen als außerordentlich problematisch. Zum einen bestanden in den frühen $1950 \mathrm{er}$ Jahren im Ausland, vor allem in den USA, nur wenige diplomatische Vertretungen der Bundesrepublik Deutschland. Da es unerlässlich war, dass sowohl Antragsteller als auch Zeugen zur Klärung der Sachlage in einer deutschen Gesandtschaft persönlich vorstellig wurden, mussten die Betroffenen oft Hunderte von Kilometern anreisen. So gab das Generalkonsulat in New York in einem Schreiben vom September 1952, also kurz nach Anlaufen der Aktion, an das Auswärtige Amt zu bedenken, dass die persönliche Vernehmung eines Antragstellers, der 700 Kilometer weit entfernt von New York wohne, mit entsprechenden Kosten verbunden sei. ${ }^{77}$ Abgesehen von dem erheblichen Aufwand an Zeit und den mit der Reise verbundenen Strapazen gingen die Reisekosten, die den Betroffenen von den Auslandsvertretungen erstattet wurden, zu Lasten der für die Wiedergutmachung bereitgestellten Mittel.

Zum anderen waren die Auslandsvertretungen mit der ihnen anvertrauten Aufgabe völlig überlastet, ${ }^{78}$ zumal sich im Verlauf der Aktion herausstellte, dass man die Zahl der Geschädigten in Bonn grob unterschätzt hatte. Statt den vorgeschriebenen Bearbeitungsmodus unter diesen Umständen zu lockern, erachtete das Bundesministerium der Finanzen jetzt eine Verschärfung der Ermittlungsmaßnahmen für notwendig. Die deutschen Gesandtschaften erhielten demzufolge die Anweisung, bei der Prüfung der Anträge „mit er-

73 Runderlass vom 9.5.1952, PA/AA, Abt. II, Bd. 1664.

74 BMF an AA, 30.9.1952, BA, B 126/12553.

75 Runderlass vom 7.4.1952, BA, B 126/12553.

$76 \mathrm{BMF}$ an Bundeswirtschaftsministerium, o.D., BA, B 126/12554; Auszahlungen von Entschädigungsleistungen wurden zu Lasten des Devisenglobalkontingents, das dem Auswärtigen Amt zugeteilt war, durchgeführt, vgl. Bundeswirtschaftsministerium an BMF, 28.5. 1952, BA, B 126/12554.

77 Generalkonsulat New York an AA, 2.9.1952, BA, B 126/12553.

78 „Der Sozialreferent des Generalkonsulats hat darum in erheblichen Überstunden und unter $\mathrm{Zu}$ rückstellung anderer dringlicher Aufgaben die Bearbeitung der hier noch vorliegenden [...] Anträge in diesen Tagen abgeschlossen." Generalkonsulat Amsterdam an AA, 6. 10. 1952, PA/AA, B 81/147. 
höhter Genauigkeit“ vorzugehen, da „mit einem vermehrten Eingang von unbegründeten Anträgen zu rechnen sei“. ${ }^{79}$ Der Hinweis, dass die Bearbeitung der Anträge durch das umstrittene Nachprüfverfahren außerordentlich crschwert und das Verhältnis zwischen Auslandsvertretungen und Antragstellern unnötig belastet würde, war in diesem Zusammenhang berechtigt, blieb aber unbeachtet. ${ }^{80}$

Tatsächlich sahen sich die deutschen Dienststellen im Ausland angesichts der strikten Weisungen aus Bonn mit einer ganzen Reihe von administrativen Schwierigkeiten konfrontiert. Das Generalkonsulat in Amsterdam kritisierte, dass eine klare und erschöpfende Beurteilung jedes Einzelfalles nicht erbracht werden könne, da zu wenig amtliche Dokumente für die erforderlichen Untersuchungen vorhanden seien. Selbst die grundlegende Frage, ob es sich im Einzelfall um einen Menschenversuch im Sinne des Kabinettsbeschlusses gehandelt habe, konnte von den Auslandsvertretungen nicht in verantwortungsvoller Weise geklärt werden, da es das Bundesfinanzministerium trotz unzähliger Durchführungsverordnungen versäumt hatte, den Begriff „Menschenversuch“ genauer zu definieren. ${ }^{81}$

Zwar sollte das Buch „Der SS-Staat“ von Eugen Kogon ${ }^{82}$, das eine kurze Darstellung der durchgeführten Experimente enthielt, allen Gesandtschaften als Informationsquelle zur Verfügung gestellt werden, doch auch dies verlief nicht reibungslos. Die Deutsche Botschaft in Montreal musste mehrmals dringlich um Zusendung der angekündigten Publikation bitten, da der zuständige Sachbearbeiter mangels Kenntnis der Verbrechensgeschichte bei den Ermittlungen zwei Jahre nach Erlass des Kabinettsbeschlusses immer noch im „Dunkeln tappte“. ${ }^{83}$

Der Schriftverkehr zwischen deutschen Gesandtschaften und Auswärtigem Amt macht deutlich, dass der vom Bundesfinanzministerium vorgegebene Fahrplan für die Wiedergutmachung bei überlebenden Opfern von Menschenversuchen keineswegs die geeignete Methode für den erwünschten reibungslosen Ablauf der Aktion darstellte. So lassen die Stellungnahmen verschiedener Auslandsvertretungen erkennen, dass die Verbindung des Entschädigungsprinzips mit fürsorgerischen Erwägungen angesichts der Reaktionen der Antragsteller zu erheblichen Schwierigkeiten führte. Das Deutsche Generalkonsulat in New York wies darauf hin, dass „ein Antragsteller verbittert wird und die deutschen Behörden der Unaufrichtigkeit zeihen könnte, wenn ihm nach langwieriger Überprüfung des Falles eröffnet wird, daß sein Vorbringen zwar ausreichend bewiesen, jedoch mangels Vorliegen einer wirtschaftlichen Notlage im Sinne des Kabinettsbeschlusses nicht rechtserheblich sei“. ${ }^{84}$ Nicht zuletzt „aus psychologischen Gründen “ hielt auch das Generalkonsulat in Amsterdam eine generelle Ablehnung der Anträge von körperlich besonders schwer geschädigten, aber nicht „bedürftigen“ Opfern für unvertretbar. In den Mittelpunkt des Wiedergutmachungsgedankens solle vielmehr die Tatsache gestellt werden, dass an den Überlebenden überhaupt medizinische Experimente vorgenommen worden waren. Der Vorschlag, den Geschädigten ohne Rücksicht auf das Vorliegen einer Notlage Hilfe zuteilwerden zu lassen und ihnen je nach Bedürftigkeit Zusatzleistungen zuzubilligen, wurde jedoch vom Bundesfinanzministerium abgelehnt, da es sich bei dem Kabinettsbeschluss um eine auf Härtefälle beschränkte „Überbrückungsmaßnahme“ handele. ${ }^{85}$ Die Antragsteller, die man-

79 BMF an AA, 2.8.1952, PA/AA, B 81/147.

80 Generalkonsulat Amsterdam an AA, 17.9.1951, PA/AA, B 81/147.

81 Generalkonsulat Montreal an AA, 12.4.1953, PA/AA, B 81/147.

82 Kogon, SS-Staat.

83 Generalkonsulat Montreal an AA, 12.4.1953, PA/AA, B 81/147.

${ }^{84}$ Generalkonsulat New York an AA, 16. 10.1952, PA/AA, B 81/147.

85 BMF an AA, 17. 1. 1952, PA/AA, B 81/147. 
gels Vorliegen einer wirtschaftlichen Notlage abgewiesen worden waren, wurden von den Auslandsvertretungen auf eine kommende Entschädigungsgesetzgebung vertröstet. Wie der Botschafter in Montreal im Jahr 1953 zutreffend prognostizierte, wurden durch diese „Hinhaltetaktik“ bei den Betroffenen Hoffnungen geweckt, „die sich möglicherweise nicht so bald oder vielleicht nie erfüllen" sollten.$^{86}$ Dem deutschen Ansehen wurde durch diese Regelung ein Schaden zugefügt, der in keinem Verhältnis zu den etwaigen finanziellen Leistungen für die wenigen überlebenden Opfer von Menschenversuchen stand.

Im Hinblick auf die besondere Aufmerksamkeit, mit der im Ausland die Wiedergutmachung für Opfer von Menschenversuchen beobachtet wurde, schien der deutschen Auslandsvertretung in Amsterdam eine beschleunigte Abwicklung der Hilfsaktion geboten. ${ }^{87}$ Auch nach Ansicht des Auswärtigen Amts war eine weitere Verzögerung der Zahlungen nicht ratsam. In einem Schreiben an das Bundesfinanzministerium setzte sich Legationsrat Heinz Trützschler von Falkenstein angesichts der politischen Dimension der Aktion dafür ein, den Antragstellern nach summarischer Überprüfung der Anträge wenigstens Vorschussleistungen zuzubilligen. Vor allem die Vereinten Nationen hatten wiederholt ihr Interesse an der Angelegenheit bekundet. ${ }^{88}$

Obwohl auf die Bedeutung dieser Frage für den moralischen Kredit der Bundesrepublik Deutschland im Ausland ausdrücklich hingewiesen worden war, zeigte sich das Bundesfinanzministerium jedoch auch in diesem Punkt nicht kompromissbereit. ${ }^{89}$ Begründet wurde die restriktive Haltung mit dem Hinweis, dass eine Zuwendung von Bundesmitteln nicht vertretbar sei, solange der Sachverhalt nicht in jedem Einzelfall einwandfrei geklärt sei. Eine Sonderlösung zugunsten Einzelner sollte unter allen Umständen vermieden werden, da man befürchtete, dass durch Vorschusszahlungen Entscheidungen über künftige Anträge präjudiziert werden könnten. ${ }^{90}$

Grundsätzlich erreichten das Bundesfinanzministerium und die deutschen Gesandtschaften hinsichtlich der Bearbeitungspraxis in vielen Punkten keine Übereinstimmung. So kam es, dass man sich in Bonn bei der Beurteilung der einzelnen Fälle über die Stellungnahmen der Auslandsvertretungen hinwegsetzte, obwohl diese nur selten Zweifel am Wahrheitsgehalt der Aussagen anmeldeten und die Glaubwürdigkeit der Antragsteller meist aufgrund der Zusammenarbeit mit örtlichen Hilfsorganisationen nachgeprüft werden konnte. ${ }^{91}$ Aus den einschlägigen Akten geht hervor, dass eine ganze Reihe von Anträgen trotz eindeutiger Anspruchsbejahung durch den Sachbearbeiter im Ausland vom Interministeriellen Ausschuss abschlägig beschieden wurde. ${ }^{92}$

86 Generalkonsulat Montreal an AA, 12.4. 1953, PA/AA, B 81/147.

87 Stellungnahme des Generalkonsulats Amsterdam zum Stand der Aktion an AA, 6. 10. 1952, PA/AA, B $81 / 147$.

88 Trützschler, AA, an Schäffer, BMF, 17.3. 1952, PA/AA, Abt. II, Bd. 1664.

89 Aktenvermerk Schmidts vom 3.4.1952, über eine Besprechung zwischen Vertretern des AA und dem BMF, PA/AA, Abt. II, Bd. 1664.

${ }^{90} \mathrm{BMF}$ an AA, 8.3.1952, PA/AA, B 81/147.

91 „Beide Auslandsvertretungen versichern, daß sie gute Verbindungen zu jüdischen und anderen Organisationen haben [...], und daß es möglich wäre, durch Nachfrage oder Einsichtnahme in die Akten eine objektive Beurteilung zu erreichen." AA an BMF, 15.12. 1951, PA/AA, B 81/147.

92 So hatte das Auswärtige Amt das Bundesfinanzministerium gebeten, sechs Fälle zu überprüfen, bei denen die Deutsche Gesandtschaft in Stockholm die Voraussetzung für eine Fürsorgeleistung bejaht hatte, die aber alle vom Interministeriellen Ausschuss negativ beschieden wurden, vgl. AA an BMF, 19.8.1954, BA, B 126/12554. 
So bestätigte das Deutsche Generalkonsulat in Montreal mit Schreiben im März 1955 im Fall von Frau Halina S., dass die Aussagen der Antragstellerin über die an ihr vorgenommenen Humanexperimente in Ravensbrück glaubwürdig seien. Zudem sei sie bedürftig, so dass in diesem Fall eine großzügige und schnelle Hilfe angebracht sei. ${ }^{93}$ Im Januar 1956 also zehn Monate später - erhielt Frau S. jedoch einen abschlägigen Bescheid vom Bundesministerium der Finanzen, mit der Begründung, dass die Voraussetzungen für die Gewährung einer Beihilfe bei ihr nicht vorlägen..$^{94}$

Dass es bei solchen Urteilen, die rein nach Aktenlage und ohne Anhörung des Antragstellers getroffen wurden, zu einer beträchtlichen Anzahl von zweifelhaften Entscheidungen kommen musste, lag auf der Hand. Der Mensch mit seinem Schicksal wurde zum abgestempelten Fall, da die bürokratische Realität paragrafensicher und damit emotionslos sein sollte. Verschiedene Stellungnahmen von Auslandsvertretungen zeigen, dass sich die Sozialreferenten, die vor Ort mit den menschlichen Schicksalen konfrontiert waren, ihrer hohen Verantwortung bewusst waren. Warum die Bonner Behörden, allen voran das Bundesfinanzministerium, die zahlreich vorgebrachten und durchaus praktikablen Verbesserungsvorschläge bezüglich der Abwicklung ignorierten, ist angesichts der politischen Tragweite dieser Aktion und insbesondere im Hinblick auf die im Kabinettsbeschluss eigens statuierte moralische Verpflichtung gegenüber den Betroffenen nicht verständlich. In dem angestrengten Bemühen, den Haushalt nicht durch vermeintlich unberechtigte Entschädigungsleistungen zu belasten, schoss das Bundesfinanzministerium vielmehr weit über das Ziel hinaus. Tatsächlich wäre dem Grundsatz der Verhältnismäßigkeit weitaus mehr Rechnung getragen worden, hätte man mehr Raum für Individualgerechtigkeit gelassen. Stattdessen wurde der zur Verfügung stehende Etat noch durch umfangreiche Ermittlungen unnötig strapaziert.

Während der Kabinettsbeschluss unter der Prämisse erlassen worden war, den Opfern unbürokratisch zu helfen, führte die strenge bürokratische Vorgehensweise dazu, dass das erforderliche Fingerspitzengefühl auf der Strecke blieb. Die deutschen Auslandsvertretungen standen vor der Herausforderung, Recht und Menschlichkeit miteinander zu verbinden. Diese ohnehin schwer zu bewältigende Aufgabe wurde ihnen durch die unkooperative Haltung des Bundesfinanzministeriums so gut wie unmöglich gemacht. Im Fall der Wiedergutmachung für überlebende Opfer von Menschenversuchen arbeitete der Verwaltungsapparat starr in hierarchischer Weise. Die Zuständigkeiten waren klar verteilt: „Oben“ wurde angewiesen und „unten“ umgesetzt. Die diplomatischen Vertretungen, die als ausführende Instanzen für die in Bonn getroffenen Entscheidungen im Ausland die Verantwortung übernehmen mussten, sahen sich außer Stande, auf die teilweise vehemente Kritik von Betroffenen und Interessenverbänden in angemessener Weise zu reagieren, da ihnen aufgrund der restriktiven Weisungen die Hände gebunden waren. Eine großzügigere Auslegung der vorgegebenen Richtlinien führte wiederum umgehend zu Beanstandungen seitens des Bundesfinanzministeriums. ${ }^{95}$

93 Generalkonsulat Montreal an AA, 16.3.1955, PA/AA, B 81/978.

94 Blessin, BMF, an Halina S., 31. 1.1956, PA/AA, B 81/978.

95 Blessin, BMF, an AA, 2. 4. 1954, BA, B 126/12553. 


\section{Das Problem der Wahrheitsermittlung im Entschädigungsverfahren}

Die erste Sitzung des Interministeriellen Ausschusses, in der von zwanzig behandelten Fällen nur vier Fälle positiv entschieden wurden, fand im Mai 1952 statt. Ein Vertreter des Auswärtigen Amts, der an dieser Sitzung teilgenommen hatte, äußerte in einem Aktenvermerk konkrete Bedenken bezüglich der Anwendung des Kabinettsbeschlusses und prognostizierte damit den weiteren Verlauf der Wiedergutmachung für Opfer von Menschenversuchen: „Obwohl in der ersten Besprechung von allen Seiten der Wunsch betont wurde, die Regelung möglichst großzügig zu handhaben, werden wahrscheinlich die meisten Fälle ablehnend beschieden werden." 96

Sucht man nach den Ursachen für diese restriktive Verfahrensweise, muss man zunächst die administrative Praxis näher beleuchten. Schon die ergänzenden Ausführungen zu der Sonderregelung von 1951 sahen eine klare Abgrenzung des Personenkreises vor. So sollte die Unterstützung nach Fürsorgegesichtspunkten in Fällen erfolgen, in denen eine Hilfe notwendig und gerechtfertigt sei, jedoch nur unter genauer Überprüfung der Anspruchsberechtigung. Voraussetzung für die Anerkennung als Opfer von Menschenversuchen war zunächst die einwandfreie Feststellung, dass im einzelnen Fall ein unzulässiges Experiment vorgenommen worden war. ${ }^{97}$ Auf Rückfrage des Bundesfinanzministeriums bestätigte der Internationale Suchdienst Arolsen soweit möglich die einzelnen Daten, wodurch die Identität des Antragstellers sowie Tatsache und Dauer der Haftzeit in einem Konzentrationslager anhand der Häftlingsnummer beziehungsweise durch Inhaftierungsbescheinigungen überprüft werden konnten. ${ }^{98}$

Die diplomatischen Vertretungen der Bundesrepublik wurden angewiesen, sowohl Zeugen zu dem jeweiligen Sachverhalt zu vernehmen als auch Auskünfte über den Leumund, die soziale Stellung und die Bedürftigkeit des Antragstellers einzuholen. Unerlässlich war ferner die Erstellung eines Gutachtens durch einen Vertrauensarzt, um den Ursachenzusammenhang zwischen der dauernden Gesundheitsschädigung und dem vorgenommenen Experiment zu belegen. ${ }^{99}$ Nach Ansicht des Bundesfinanzministeriums war diese sorgfältige Ermittlungsarbeit durchaus notwendig, „um betrügerische Machenschaften der Antragsteller von vornherein auszuschalten ". ${ }^{100}$ Der Spielraum für Ermessensentscheidungen wurde damit so eng begrenzt, dass trotz der Verschiedenartigkeit der Verfolgungsschicksale und der Beweisprobleme der Antragsteller für die Härteregelung nur Personen in Frage kamen, gegen deren Anträge keinerlei Bedenken bestanden.

Bei der Beurteilung, ob es sich im Einzelfall um einen Menschenversuch gehandelt hatte, hielt sich der Interministerielle Ausschuss grundsätzlich an Tatbestände, die im Nürnberger Ärzteprozess zur Verhandlung gekommen waren. ${ }^{101}$ Zur Beweisführung wurden auBerdem die Dokumentation „Wissenschaft ohne Menschlichkeit“ von Alexander Mitscherlich und Fred Mielke sowie das Kapitel „Reihenversuche unzulässiger Art“ aus dem Buch

96 Aktenvermerk Biermanns vom 8.5.1952, betr. Erste Sitzung des Interministeriellen Ausschusses zur Festsetzung der Fürsorgezahlungen für Opfer von Menschenversuchen, PA/AA, Abt. II, Bd. 1663.

97 BMF, Schmidt, an AA, 30.9. 1952, BA, B 126/12553.

98 AHK, International Tracing Service, an BMF, 10.2. 1954, BA, B 126/12554.

99 BMF an AA, 13.3. 1952, BA, B 126/12554.

100 AA an Generalsekretär der Vereinten Nationen, Stellungnahme zu Entwurf und Durchführung des Kabinettsbeschlusses vom 30.7.1951, BA, B 126/12554.

101 BMF an AA, Tätigkeitsbericht vom 27.11. 1957, BA, B 126/61084. 
„Der SS-Staat" von Eugen Kogon herangezogen. ${ }^{102}$ Zwar basieren beide Dokumentationen auf den Ergebnissen des Alliierten Gerichtshofs. Da in Nürnberg jedoch nicht alle Verbrechenskategorien zur Verhandlung gekommen waren, konnten die Tatbestände aufgrund des Prozessmaterials nur lückenhaft dargestellt werden.

Für die Betroffenen war es mitunter außerordentlich folgenschwer, dass der jeweilige Entscheidungsträger über eine ungenügende Kenntnis der Verfolgungsgeschichte verfügte. Zu Recht übte daher die Französische Botschaft in Bonn Kritik an dieser Verfahrensweise und wies darauf hin, dass die Ablehnung eines Antrags nicht ausreichend gerechtfertigt sei, wenn der angegebene Versuch nicht in die bekannt gewordenen Verbrechenskategorien eingeordnet werden könne. ${ }^{103}$ Obwohl durch die Anträge auf Wiedergutmachung neue Tatbestände aufgedeckt wurden, zeigte der Interministerielle Ausschuss in der Entschädigungspraxis wenig Anpassungsfähigkeit. Die mangelnde Bereitschaft, sich mit den unterschiedlichen Verfolgungsschicksalen auseinanderzusetzen, wirkte sich in doppelter Hinsicht negativ für die Betroffenen aus: Während auf der einen Seite die genaue Rekonstruktion der Verbrechensgeschichte, die für eine gewissenhafte Überprüfung der Anträge die notwendige Voraussetzung gewesen wäre, blockiert wurde, begünstigte die geringe Kenntnis der Verfolgungswirklichkeit bei der Beurteilung von Menschenversuchen wiederum restriktive Entscheidungen.

In einer internen Stellungnahme rechtfertigte das Bundesfinanzministerium diese Verfahrensweise mit folgender Begründung: Da fast jede medizinische Behandlung mehr oder weniger einen Versuch darstelle, könne der Begriff des „medizinischen Versuchs“ nicht eindeutig geklärt werden. Zweifellos seien in den Konzentrationslagern zwar auch „private Versuche“ vorgenommen worden, „um aber nicht ins Uferlose zu kommen“, müsse sich der Interministerielle Ausschuss grundsätzlich an die im Ärzteprozess bekannt gewordenen Tatbestände halten. ${ }^{104} \mathrm{In}$ einem Schreiben an das Auswärtige Amt behauptete der Vertreter des Bundesministeriums der Finanzen, Georg Blessin, dass der Interministerielle Ausschuss in Zweifelsfällen stets zugunsten der Antragsteller einen unzulässigen Menschenversuch unterstelle und daher in solchen Fällen Beihilfen gewähre. ${ }^{105}$ Die praktische Umsetzung bewies jedoch in vielen Fällen das Gegenteil.

Das Bundesfinanzministerium verstieg sich in der Frage der Entschädigung für Opfer von Sterilisationsexperimenten zu der Äußerung, dass es sich bei den Eingriffen um „Unfruchtbarmachungen“ gehandelt habe, die aus rassischen und politischen Gründen durchgeführt worden seien und damit keine diskriminierenden Versuche darstellten. „Weitere 59 Anträge wegen Sterilisierung mussten von vornherein abgelehnt werden", geht aus einem Tätigkeitsbericht des Bundesfinanzministeriums vom September 1952 hervor. ${ }^{106}$ Obwohl ein Blick in die normalerweise so präzise überprüften Beweisunterlagen genügt hätte, um festzustellen, dass experimentelle Versuche zur Vorbereitung von Massensterilisa-

102 Mitscherlich/Mielke, Wissenschaft ohne Menschlichkeit; Kogon, SS-Staat.

103 „Un très grand nombre d'affaires de ce genre n'a pas été porté devant cette jurisdiction, ni devant une autre, les temoins survivants aient été trop peu nombreux, soit pour tout autre motif." Aus einer Verbalnote der Französischen Botschaft in Bonn an AA vom 11.7.1955, BA, B 126/12554.

${ }^{104}$ Interne Aufzeichnung des BMF über den bisherigen Verlauf der Aktion zugunsten überlebender Opfer von Menschenversuchen, Stichtag 1.5.1958, BA, B 126/61084.

105 Stellungnahme zur Verbalnote der Französischen Botschaft in Bonn vom 11.7. 1955, in der kritisiert wird, dass Individualexperimente in vielen Fällen nicht anerkannt wurden, vgl. Blessin, BMF, an AA, Okt. 1955, BA, B 126/12554.

106 Tätigkeitsbericht des BMF vom 26.9.1952, BA, B 126/1251. 
tionen stattgefunden hatten, ${ }^{107}$ veranlasste erst scharfe Kritik aus amerikanischen Kreisen die Bundesregierung, die Frage zu klären, ob die Sterilisationsexperimente in den Konzentrationslagern hinsichtlich ihrer Zielsetzung und der medizinischen Technik mit den Sterilisierungen aufgrund der Erbgesundheitsgesetzgebung außerhalb der Lager identisch seien. ${ }^{108}$ Schließlich, ein Jahr nach einem restriktiven Runderlass an alle diplomatischen Vertretungen, revidierte der Interministerielle Ausschuss seine Ansicht, ohne jedoch den nachweislich erheblichen Unterschieden bei den Sterilisationsexperimenten Rechnung zu tragen. ${ }^{109}$

Auch Anträge, in denen sogenannte Individualexperimente angegeben worden waren, wurden grundsätzlich mit der Begründung abgelehnt, dass für die gesundheitlichen Schäden nicht die behaupteten Menschenversuche, sondern allenfalls die allgemeine Behandlung in den Konzentrationslagern ursächlich gewesen sei. ${ }^{110}$ Wiederholt musste das Bundesfinanzministerium vom Bundesverwaltungsgericht auf seine "moralische Verpflichtung“ hingewiesen werden, nachdem es seine eigene Verwaltungspraxis in gleich liegenden Fällen nicht beachtet und damit das „Willkürverbot“ im Sinne des Grundgesetzes verletzt hatte. ${ }^{111}$

Bei abschlägig beurteilten Anträgen war keine weitere Stellungnahme zu der getroffenen Entscheidung vorgesehen. In dem vom Bundesfinanzministerium abgezeichneten Bescheid hieß es in nüchternstem Amtsdeutsch:

„Ich bedauere, Ihrem Antrag auf Fürsorge als überlebendes Opfer von Menschenversuchen gemäß dem Beschluß der Bundesregierung vom 26.Juli 1951 nicht entsprechen zu können. Nach dem Ergebnis der Ermittlungen ist nicht dargetan, dass Sie als Versuchsperson für medizinische Zwecke mißbraucht worden sind."112

Einen solchen Bescheid erhielt auch Frau Piri J., die in ihrem Antrag angegeben hatte, an ihr seien im Konzentrationslager Auschwitz wiederholt „Serumbehandlungen“ durchgeführt worden, die in der Folge zu unnatürlichem männlichem Haarwuchs sowie zu einem schweren Herz- und Nervenleiden geführt hätten. Obwohl die zuständige Deutsche Botschaft in Stockholm eine Fürsorgeleistung befürwortete, verlangte das Bundesministerium der Finanzen noch Angaben darüber, ob sich Frau J. in einer wirtschaftlichen Notlage befinde. ${ }^{113}$ Die Antragstellerin beschwerte sich darüber. Schließlich habe sie sich nicht als „Kandidatin für Wohlfahrtsunterstützung“" gemeldet. Weiter hieß es in dem Schreiben verbittert: „Aber sind Sie nicht auch der Ansicht, daß ein Mensch, der durch die Experimente des Naziregimes für sein ganzes Leben verunstaltet ist, ein Mensch, der seine ganze Familie

107 Vgl. das Kapitel „Experimentelle Vorarbeiten für Massensterilisationen“, in: Mitscherlich/Mielke, Medizin ohne Menschlichkeit, S. 227-248. Auch der Psychiater Leo Alexander, der beim Ersten Amerikanischen Gerichtshof als Gutachter bestellt war, schrieb bereits 1949, dass im Rahmen von Menschenversuchen in Konzentrationslagern Sterilisations- und Kastrationsmethoden erprobt worden seien. Vgl. hierzu das Kapitel über Leo Alexander, in: Peter, Nürnberger Ärzteprozeß, S. 120.

108 Generalkonsulat New York an AA, 16. 10. 1952, PA/AA, B 81/147.

109 Von den drei methodisch verschiedenen Sterilisationsexperimenten (Röntgensterilisation, medikamentöse Sterilisation, Sterilisation durch intrauterine Reizwirkung) wurde nur letzteres als entschädigungspflichtig anerkannt, vgl. Runderlass des AA an alle diplomatischen und berufskonsularischen Vertretungen vom 2.2.1953, BA, B 126/12553.

110 BMF an BMI, 10.9. 1954, BA, B 126/12554.

"I Siehe hierzu Beispiele in dem Kapitel „Menschenversuch“, in: Fischer-Hübner (Hrsg.), Kehrseite der „Wiedergutmachung“, S. 139-147.

112 Aus einem Ablehnungsbescheid des BMF vom 18.8.1954, BA, B 126/12554.

113 Botschaft Stockholm an Frau Piri J., 25.9. 1952, PA/AA, B 81/978. 
im KZ-Lager verloren und dortselbst seine Jugend verbracht hat und die letzten sieben Jahre verunstaltet in banger Sorge um seine Zukunft lebt, es einfach nicht begreifen kann, daß ein Staat, der wiedergutmachungswillig ist, sich in einem Fall, wie dem meinigen, auf formaljuristische Formen beruft." 114 Ein halbes Jahr später wurde der Antrag seitens des Bundesfinanzministeriums abgelehnt, mit der Begründung, die gesundheitlichen Schäden seien „wahrscheinlich anlagemäßig bedingt". ${ }^{115}$

Zwar verlangte das United Restitution Office ${ }^{116}$ in Stockholm, das sich für die Wiedergutmachungsansprüche von Betroffenen einsetzte, in offensichtlichen Zweifelsfällen eine Überprüfung der abgelehnten Anträge durch eine nochmalige ärztliche Untersuchung, ${ }^{117}$ der Forderung wurde aber nicht entsprochen, da sich nach Ansicht des Bundesfinanzministeriums keine neuen Gesichtspunkte, die zu einer anderen Beurteilung der Anträge Anlass geben könnten, gewinnen ließen. ${ }^{118}$ Aus einem regierungsinternen Schriftwechsel geht indes hervor, dass man von der bisherigen Verfahrensweise vor allem aus finanzpolitischen Gründen nicht abrücken wollte. Außerdem sollte unter allen Umständen vermieden werden, dass in Zukunft auch anderen Personen, deren Beihilfeanträge abgelehnt worden waren, das Recht auf eine zweite Überprüfung der Anträge eingeräumt werde. ${ }^{119}$

Die Kritik, dass die Wiedergutmachungsverwaltung in der Bundesrepublik nur „schleppende Arbeit" geleistet habe, zieht sich wie ein roter Faden durch die Geschichte der Wiedergutmachung. ${ }^{120}$ Die Entschädigungspraxis bei überlebenden Opfern von Menschenversuchen bildet hier keine Ausnahme. Knapp ein Jahr nach Erlass des Kabinettsbeschlusses hatte der Interministerielle Ausschuss keinen einzigen der zahlreich eingegangenen Anträge entschieden, obwohl die Bundesregierung den Geschädigten seinerzeit eine wirksame Hilfeleistung zugesichert hatte. Seitens der Betroffenen wurden daher Stimmen laut, die den guten Willen der Bundesregierung in Zweifel zogen. ${ }^{121}$ Auch das Auswärtige Amt, das durch die diplomatischen Vertretungen über die negativen Reaktionen im Ausland in Kenntnis gesetzt wurde, gab gegenüber dem Bundesfinanzministerium zu bedenken, dass sich unter diesen Umständen der günstige Eindruck, den die Aktion seinerzeit im Ausland hervorgerufen habe, verflüchtigen werde. „Das Wort, doppelt gibt, wer schnell gibt” müsste indes gerade gegenüber den Opfern von Menschenversuchen besonders beherzigt werden."122

Die Behauptung des Bundesfinanzministeriums, dass jeder Antrag auf Fürsorge für überlebende Opfer von Menschenversuchen sofort bearbeitet werde, ${ }^{123}$ entsprach keineswegs der tatsächlichen Vorgehensweise des Interministeriellen Ausschusses. Grundsätzlich wur-

\footnotetext{
114 Piri J. an Botschaft Stockholm, 27.10.1952, PA/AA, B 81/978.

115 Schmidt, BMF, an Piri J., 3. 7. 1953, PA/AA, B 81/978.

116 Das URO wurde 1948 als international tätige, gemeinnützige Rechtshilfeorganisation mit Sitz in London gegründet; zur Geschichte des URO vgl. Hockerts, Anwälte der Verfolgten.

117 „Die Wiedergutmachungsberechtigten [...] - vertreten durch das United Restitution Office (URO) in Stockholm - haben um erneute Überprüfung ihrer abgelehnten Anträge gebeten. " Botschaft Stockholm an AA, 3.8. 1954, BA, B 126/12554.

118 BMF an AA, betr. Überprüfung der Schwedenfälle, 26.10. 1954, BA, B 126/12554.

119 BMI an BMF, 23.9. 1954, BA, B 126/12554.

120 Etwa Rothe, „Schleppende“ Arbeit.

121 „Es ist nur zu häufig vorgekommen, daß Fälle, die offensichtlich hätten berücksichtigt werden müssen, vom Ausschuss einfach beiseitegeschoben worden sind." ADIR an BMF, Wolff, 28. 7. 1956, BA, B $126 / 61084$.

${ }^{122}$ AA an BMF, 17.3. 1952, PA/AA, Abt. II, Bd. 1663.

$123 \mathrm{BMF}$ an AA, 27. 11. 1957, PA/AA, B 81/215.
} 
den Verfahren zurückgestellt, bei denen die Antragsteller gleichzeitig Ansprüche nach dem Bundesentschädigungsgesetz angemeldet hatten. Vorläufig nicht erledigt wurden ferner Anträge von Personen in Ländern, mit denen die Bundesrepublik Deutschland keine diplomatischen Beziehungen unterhielt. Ganze Gruppen von Wiedergutmachungsfällen wurden teilweise nicht entschieden, weil die Klärung einer dafür wesentlichen Frage, meist im Zusammenhang mit der Verbrechensgeschichte, von einer Grundsatzentscheidung abhängig gemacht wurde. Im Fall der Sterilisationsexperimente wurde diese Entscheidung zum Beispiel erst im Jahr 1953 getroffen. ${ }^{124}$

Erschwerend kam hinzu, dass die Finanzbehörde nur schrittweise die notwendigen Durchführungsverordnungen erließ, die für eine zügige Abwicklung der Verfahren unerlässlich waren. In zahlreichen anderen Fällen führten die zeitraubenden Ermittlungen aufgrund der strengen Überprüfungskriterien zu gravierenden Verzögerungen in der Bearbeitung der Anträge. So wurde in Anweisungen des Bundesfinanzministeriums eine in alle Einzelheiten gehende Ermittlung der Schadenstatbestände gefordert, wobei in Kauf genommen wurde, dass sich die Entschädigungsverfahren damit vielfach in einer für die Antragsteller unzumutbaren Weise über Jahre hinzogen. ${ }^{125}$

\section{Die Erfahrungsgeschichte der Antragsteller in den Verfahren}

Auch in vielen anderen Wiedergutmachungsverfahren gaben die langwierigen Ermittlungen der Behörden oft Grund zur Beanstandung. Die anfangs postulierte Verantwortung der Entschädigungsbehörde gegenüber den zu Unrecht Verfolgten versickerte in einem bürokratischen System, das die genaue Einhaltung von Richtlinien und die detaillierte Überprüfung der Anspruchsberechtigung zum obersten Grundsatz erhob. Obwohl die besondere, durch die nationalsozialistische Verfolgung geschaffene Situation die Zulassung von Beweiserleichterung geboten hätte, mussten die Behörden unter allen Umständen darauf achten, dass ihnen bei den Verfahren keine Unterlassung bei der Wahrheitsermittlung vorgeworfen werden konnte. ${ }^{126}$ Der Argwohn gegenüber etwaigem Missbrauch von Entschädigungsleistungen übertrug sich auf die Behandlung einwandfreier Fälle. Dies hatte zur Folge, dass die Antragsteller oft langen und quälenden Verhandlungen ausgesetzt waren, die am Ende zu keiner angemessenen Entschädigung führten.

Der oft jahrelange Kampf mit den damit verbundenen psychischen Belastungen führte dazu, dass viele Betroffene resignierten und auf die ihnen zustehenden Entschädigungsleistungen verzichteten. So gab es gerade im Bereich der Körper- und Gesundheitsverfahren einen unverhältnismäßig hohen Anteil an stillstehenden Prozessen, da Tausende von Verfahren ohne formale Erledigung im Sande verliefen. ${ }^{127}$ Wurde ein Antrag ganz oder teilweise abgelehnt, war der Antragsteller gezwungen, seinen Anspruch gerichtlich durchzusetzen. Das verstärkte die Ressentiments gegenüber dem deutschen Behördenapparat. Antragsteller und Bevollmächtigte waren häufig der Überzeugung, dass die Entschädi-

124 Runderlass des AA an alle diplomatischen und berufskonsularischen Vertretungen vom 2.2.1953, BA, B 126/12553.

125 „Dabei verkenne ich nicht, daß die Geduld der Geschädigten mit Rücksicht auf die zeitraubenden, indessen nicht vermeidbaren Ermittlungen vielfach auf eine harte Probe gestellt wird." BMF an AA, 8.3.1952, PA/AA, B 81/147.

126 Rothe, „Schleppende“ Arbeit, S. 359.

127 Steinbach, Prozeßstillstand. 
gungsbeamten sie entweder vorsätzlich um ihre Ansprüche bringen wollten oder dass Leichtfertigkeit, mangelndes Verständnis für ihr Schicksal oder gar staatliche Schikane zu der negativen Entscheidung geführt hätten. Die Versachlichung des Wiedergutmachungsverfahrens musste geradezu unweigerlich zu einem Konflikt zwischen der Erfahrung der Verfolgten und der Logik der Behörden führen.

Betrachtet man die Wiedergutmachung bei Opfern von Menschenversuchen, ist es verständlich, dass das Misstrauen der Betroffenen, die Exekutive wolle die guten Absichten der Regierung hintertreiben, stets wach blieb. So forderte das Bundesfinanzministerium unmissverständlich für jeden einzelnen Fall eine Überprüfung der Angaben „unter Erschöpfung aller zugänglichen Beweismittel“, ${ }^{128}$ ohne zu berücksichtigen, dass eine Ermittlung der wirklichen Verhältnisse unweigerlich auf Schwierigkeiten stoßen und zu unbefriedigenden Ergebnissen führen musste. Die damit verbundene zeitraubende Arbeitsweise des Interministeriellen Ausschusses trug weit weniger dazu bei, zwischen begründeten und unbegründeten Anträgen in verantwortungsvoller Weise zu unterscheiden, als dass sie zu einem fragwürdigen Verfahren führte. Denn je mehr Zeit zwischen dem Verfolgungstatbestand und dem Entschädigungsverfahren verging, desto größer wurden die Schwierigkeiten in der Wahrheitsermittlung - eine Tatsache, die für jeden alltäglichen Rechtsstreit zutrifft und schon aus diesem Grund nicht hätte ignoriert werden dürfen. Im Übrigen ist zu bezweifeln, ob auf diese Weise der grundsätzlich garantierte „effektive Rechtsschutz“ noch in angemessener Weise gewährleistet werden konnte. ${ }^{129}$

In vielen Fällen waren die für die Überprüfung von Entschädigungsansprüchen erforderlichen Unterlagen durch Kriegsereignisse verloren gegangen oder kurz vor Kriegsende bewusst vernichtet worden. Trotzdem glaubte man den Aussagen der Antragsteller oft nicht oder zog - schlimmer noch - fragwürdige Beweismittel heran. So empfand es das Bundesfinanzministerium als durchaus legitim, einen Arzt, der im Konzentrationslager Natzweiler an Häftlingen Versuche mit Phosgengas vorgenommen hatte, als Berater für die Entschädigungsfragen zu diesem Komplex hinzuzuziehen. ${ }^{130}$ Dieser Arzt, dessen Interesse natürlich darin bestand, den gewaltverbrecherischen Charakter seiner Handlungen zu verharmlosen, stellte die Situation so dar, als hätten sich alle Versuchspersonen freiwillig zur Verfügung gestellt, ferner „habe keine Person einen Gesundheitsschaden davon getragen, und Dauerschäden seien völlig ausgeschlossen ". ${ }^{131}$ Durch solche Falschaussagen wurden die Antragsteller in die prekäre, meist aussichtslose Situation gebracht, das Gegenteil beweisen zu müssen.

Zwar hatten die Antragsteller nicht nur die Möglichkeit, sondern sogar die Verpflichtung, in Wiedergutmachungsverfahren mitzuwirken, doch auch diese Regelung musste sich nicht notwendig zu ihren Gunsten auswirken. ${ }^{132}$ Vielmehr drängt sich die Vermutung auf, dass seitens der Behörden nicht selten aus der Beweisnot der Antragsteller Vorteil gezogen wurde, da sogenannte Zweifelsfälle vorschnell abgelehnt wurden. Den Betroffenen

\footnotetext{
128 BMF an AA, 13.3. 1952, BA, B 126/12554.

129 Damit wird das Recht auf einen wirksamen und zeitgemäßen Rechtsschutz bezeichnet.

130 „Prof. Dr. B. erklärte, dass die Namen der Versuchspersonen feststünden. Er sei bereit, noch weitere Unterlagen erforderlichenfalls zur Verfügung zu stellen und auch persönlich Auskünfte zu erteilen." Vermerk Blessins, BMF, vom 9.2. 1956, über ein Gespräch mit Prof. Bickenbach im BMF, BA, B $126 / 61082$.

131 Ebd.

132 Die Verfolgten hatten eine sogenannte Mitwirkungspflicht, vgl. Rothe, "Schleppende“ Arbeit, S. 359 .
} 
hingegen wurde das Unmögliche zugemutet: Sie sollten eindeutige Beweise für den Verfolgungstatbestand, Zeugen der Misshandlungen und medizinische Unterlagen aus der Zeit nach der Befreiung liefern, die unter den gegebenen Umständen meist nicht erbracht werden konnten. Dem Geist der Wiedergutmachung hätte es weit mehr entsprochen, wenn die Betroffenen mittels einer zumindest eingeschränkten Beweislastumkehr von der unzumutbaren Beweisführung entbunden worden wären.

Stattdessen überprüfte das Bundesfinanzministerium die Anspruchsberechtigung bei überlebenden Opfern von Menschenversuchen mit akribischer Gründlichkeit und entwickelte eigens zu diesem Zweck einen achtseitigen Fragebogen ${ }^{133}$, der das entsprechende Formular der Vereinten Nationen an Umständlichkeit und Detailversessenheit bei weitem übertraf. ${ }^{134}$ Vom Antragsteller wurden nicht nur Angaben zu seiner Person, sondern auch über Familienangehörige verlangt, ferner mussten genaue Auskünfte über den Verfolgungstatbestand, die Einkommens- und die Vermögensverhältnisse erteilt werden. Die etwa hundert in alle Einzelheiten gehenden Fragen mussten vollständig beantwortet werden, außerdem wurden die Vorlage von Beweismitteln und die Nennung von Zeugen gefordert. ${ }^{135}$ Waren Aussagen unrichtig oder unvollständig, wurde der Antrag sofort abgelehnt. Aus verschiedensten Gründen konnten oder wollten die Antragsteller unter Umständen die erforderlichen Informationen nicht erbringen. So schrieb das Deutsche Generalkonsulat in Montreal über eine Antragstellerin: „Eine hier sehr angesehene, ehemals deutsche Jüdin [...] zögerte sehr, deutsche Persönlichkeiten in massgeblicher Stellung in der Bundesrepublik als Zeugen zu benennen [...], um diese Zeugen nicht zu gefährden. "136

Bedenkt man, dass für viele Überlebende die Anmeldung von Wiedergutmachungsansprüchen den ersten Kontakt mit der Bundesrepublik darstellte, zeugen sowohl der Inhalt als auch die Verwendung des Fragenkatalogs von tiefer Verständnislosigkeit der deutschen Bürokratie gegenüber den Opfern. Die von der Verfolgung aufs Schwerste gezeichneten Menschen empfanden es als Verhöhnung ihres Schicksals, mit einer solchen Fülle von Fragen traktiert zu werden und durch den Zwang zur Rechtfertigung erneut Mechanismen ausgesetzt zu sein, die in ihren Augen einer „zweiten Verfolgung“ gleichkamen. ${ }^{137}$ Das führte bei manchen Verfolgten dazu, dass sie die schrecklichen Erfahrungen des unmenschlichen Regimes auf den neuen Staat und seine Dienststellen übertrugen.

In einem Schreiben an das Auswärtige Amt gab das Generalkonsulat in Montreal zu bedenken, dass der Fragenkatalog nicht dazu geeignet sei, den Antragstellern im Ausland vorgelegt zu werden, da die „nach den Erlassen [des Bundesfinanzministeriums] verlangte eingehende Befragung in der Sache die Opfer doch allzu peinlich an früher mit ihnen angestellte Verhöre erinnert. “138 Das Generalkonsulat in Amsterdam bat aus denselben Grün-

\footnotetext{
133 Antrag auf Fürsorge für überlebende Opfer von Menschenversuchen, BA, B 136/1153.

134 Die Vereinten Nationen hatten bereits 1950 eine Untersuchung über den Verbleib von überlebenden Opfern von Menschenversuchen eingeleitet und sich für eine Entschädigung der Betroffenen eingesetz.t. In New York gingen die ersten Anträge ein, die dort überprüft und dann nach Bonn weitergeleitet wurden. Das Auswärtige Amt hatte sich in einem Schreiben an das BMF dafür ausgesprochen, diese vereinfachten Antragsformulare zu verwenden. Der Vorschlag wurde jedoch abgelehnt. Vgl. AA, Schellert, an BMF, 15. 12. 1951, PA/AA, B 81/147.

${ }^{135}$ Antrag auf Fürsorge für überlebende Opfer von Menschenversuchen, BA, B 136/1153.

196 Generalkonsulat Montreal an AA, 12.4. 1953, PA/AA, B 81/147.

137 Der gerade bei Kritikern der Wiedergutmachung oft verwendete Begriff spielt an auf: Giordano, Die zweite Schuld; vgl. auch Pross, Wiedergutmachung.

138 Generalkonsulat Montreal an AA, 12.4.1953, PA/AA, B 81/147.
} 
den, von der Verwendung der Antragsformulare absehen zu dürfen. ${ }^{139}$ In Brüssel verweigerte eine Reihe von Antragstellern die Ausfüllung des Fragebogens, und es kam „zu unliebsamen, heftigen Widersprüchen und Vorwürfen". ${ }^{140}$ Obwohl sich angesichts solcher Zwischenfälle bei der Bearbeitung der Anträge erhebliche Schwierigkeiten abzeichneten, hielt das Bundesfinanzministerium an seinem Standpunkt fest. ${ }^{141}$ Dass sich die Wiedergutmachung in diesem Punkt den Vorwurf gefallen lassen musste, in nationalsozialistischer Manier zu arbeiten, wurde in Kauf genommen.

So verließ eine Antragstellerin unter Protest die Deutsche Botschaft in Brüssel, da sie die Art der Befragung „als eine der Gestapovernehmung ähnliche Methode“ empfand, „die nicht im Einklang mit der Erklärung der Bundesregierung stünde, das den Opfern von Menschenversuchen angetane Unrecht wiedergutzumachen “. ${ }^{142}$ Frau O., die als Halbjüdin in Deutschland gelebt hatte, war im Jahr 1938 von ihrem nichtjüdischen, deutschen Arzt geschieden worden. 1941 wurde sie von der Gestapo verhaftet und nach Auschwitz deportiert, wo man an ihr Versuche durch operative Eingriffe durchführte. Eines ihrer Kinder wurde in Auschwitz vergast, ein anderes, das sie vor der Verhaftung bei Freunden untergebracht hatte, war verschollen. Obwohl laut Angaben der Deutschen Botschaft in Brüssel alle vorgelegten Dokumente in Ordnung waren und die Aussagen der Antragstellerin bestätigten, bestand man in Bonn darauf, dass der Fragebogen ordnungsgemäß ausgefüllt werde. Im Zusammenhang mit der vertrauensärztlichen Untersuchung, die zur Erstellung eines Gutachtens notwendig war, wiederholte sich diese quälende Prozedur für jeden Antragsteller noch einmal, da nach Weisung des Bundesfinanzministeriums auch hier eine eingehende Befragung des Antragstellers vorgesehen war. ${ }^{143}$

In der Entschädigungspraxis ließen die zuständigen Behörden oft jegliches Einfühlungsvermögen für die Betroffenen vermissen. Ausgerechnet von Menschen, deren Leben von dem schrecklichen Geschehen der nationalsozialistischen Verfolgung gekennzeichnet war, wurde gegenüber deutschen Dienststellen eine umfassende Darstellung ihres Schicksals erwartet, ja sogar gefordert. Erfahrungsgemäß waren jedoch gerade die Opfer von Menschenversuchen schwer zugänglich, da sie eine nur allzu begreifliche Scheu hatten, über die belastenden Ereignisse zu sprechen. Durch die Offenlegung der körperlichen Schäden fühlten sich viele abermals bloßgestellt und entwürdigt. Das Bundesfinanzministerium schenkte dieser Tatsache keine Beachtung, sondern bezeichnete etwa die umfassenden Ermittlungen bei Opfern von Sterilisationsexperimenten als unvermeidlich. Die betroffenen Frauen waren demzufolge der demütigenden Situation ausgesetzt, die bis ins Detail gehenden Fragen - noch dazu seitens eines Mannes - über die genauen Umstände der gynäkologischen Eingriffe zu beantworten. Die Deutsche Botschaft in Montreal wies auf diese Problematik hin und bemerkte ferner, dass insbesondere die Opfer von Kastrationsversuchen den Eingriff als eine möglichst geheim zu haltende Schande empfänden. Aufgrund dieser Befangenheit wollten die Betroffenen den Gesundheitsschaden keinem größeren Personenkreis zur Kenntnis bringen. So verzichteten sie eher auf eine Entschädigungsleistung, anstatt Zeugen zu benennen, die ihr Schicksal teilten. ${ }^{144}$

139 Generalkonsulat Amsterdam an AA, 19.12.1951, PA/AA, B 81/147.

140 Botschaft Brüssel an AA, 19.11.1951, PA/AA, B 81/147.

141 BMF an AA, 17.1.1952, PA/AA, B 81/147.

142 Botschaft Brüssel an AA, 19.11.1951, PA/AA, B 81/147.

143 BMF an AA, 11.2. 1953, BA, B 136/12553.

144 Generalkonsulat Montreal an AA, 12.4. 1953, PA/AA, B 81/147. 
Selbst nach ordnungsgemäßer Beantwortung des Fragenkatalogs konnte der Antragsteller nicht unbedingt mit einer wohlwollenden Behandlung seitens der deutschen Behörden rechnen. Mit peinlicher Sorgfalt wurde die Glaubwürdigkeit der Opfer und der Zeugen überprüft. In Einzelfällen legte das Bundesfinanzministerium bei den Entscheidungen eine Haltung an den Tag, die geradezu zynisch wirken musste. So wurde das Entschädigungsgesuch eines französischen Antragstellers wegen unzureichenden Beweismaterials und fehlender Zeugen abgelehnt. Die in dieser Angelegenheit angegebenen Zeugen konnten jedoch nicht mehr aussagen, da sie einige Tage nach Durchführung der Experimente hingerichtet worden waren. ${ }^{145}$

Was im Kabinettsbeschluss als „moralische Verpflichtung“ ausgewiesen war, wurde mehr und mehr durch einen erbitterten Kampf um die „Wahrheitsermittlung“ in Frage gestellt. So ließ es sich das Bundesfinanzministerium nicht nehmen, die strenge Anwendung der in der Entschädigungsgesetzgebung vorgesehenen Behelfe gegenüber zweifelhaften Angaben auch bei dieser Verfolgtengruppe anzuwenden. ${ }^{146} \mathrm{Im}$ Wiedergutmachungsverfahren konnten grundsätzlich demjenigen Entschädigungsleistung ganz oder teilweise versagt oder entzogen werden, der mit „unlauteren Mitteln“, „vorsätzlich“ oder „grob fahrlässig“ unrichtige Angaben veranlasst oder zugelassen hatte. ${ }^{147}$

Betrachtet man die Fälle, die der Historiker Heiko Scharffenberg in seiner Studie über die Wiedergutmachung nationalsozialistischen Unrechts in Schleswig-Holstein untersuchte, drängt sich der Verdacht auf, dass diese Regelung durchaus als Vorwand benutzt wurde, um Anträge abzulehnen. ${ }^{148}$ Selbst wenn es sich lediglich um ungenaue Angaben handelte, gingen die Landesentschädigungsämter mitunter scharf vor und ahndeten die falschen Aussagen rigoros durch Entzug sämtlicher Leistungen. Dieses harte Vorgehen sollte der Abschreckung dienen, wobei keine Unterschiede zwischen kleineren Ungereimtheiten und gröberen Lügen gemacht wurden. Auch die Schwere der Verfolgung spielte in einem solchen Fall keine Rolle mehr.

Um die Anträge nach etwaiger formeller oder materieller Fehlerhaftigkeit durchforsten zu können, wurde ein entsprechender Passus auch in den „Antrag auf Fürsorge für überlebende Opfer von Menschenversuchen “ aufgenommen. ${ }^{149}$ Obwohl der Entschädigungsanwalt Joseph Wolfsohn auf die fatale Auswirkung dieser Regelung für die unter Beweisnot stehenden Antragsteller verwies und unter Hinweis auf Erklärungsmöglichkeiten dafür plädierte, die Vorschrift auch bei fahrlässiger Handlungsweise gar nicht oder mit der gebotenen Vorsicht anzuwenden, änderte der Interministerielle Ausschuss an dieser Verfahrensweise nichts. ${ }^{150}$

Schon aus psychologischen Gründen ist es verständlich, dass sich die Überlebenden nach vielen Jahren der Verfolgung nur widerstrebend alle Einzelheiten des Geschehens ins Gedächtnis rufen konnten und wollten. Oft verschmolzen quälende Wirklichkeit und Alpträume untrennbar miteinander. So macht Zdenek Zofka in seiner Studie über das „Phäno-

145 Diesbezügliche Fälle wurden von der Französischen Botschaft in Bonn in einer Verbalnote vom 11.7.1955 kritisiert, BA, B 126/12554.

146 Interne Mitteilung des BMF vom 30.3. 1954, Schmidt an Biella, BA, B 126/12553.

147 Wolfsohn, Zum Problem der Wahrheitsermittlung.

148 Scharffenberg, Sieg der Sparsamkeit, S. $180 \mathrm{f}$.

149 „Es ist mir bekannt, dass unrichtige oder unvollständige Angaben die Ablehnung meines Antrages nach sich ziehen." Antrag auf Fürsorge für überlebende Opfer von Menschenversuchen, BA, B $136 / 1153$.

${ }^{150}$ Wolfsohn, Zum Problem der Wahrheitscrmittlung, S. 152. 
men Mengele“ eindrucksvoll darauf aufmerksam, dass sich für viele überlebende Opfer der Name Mengele von der Person gelöst hatte und zum Synonym für den Lagerarzt schlechthin geworden war. Bei verschiedenen Zeugenaussagen handelte es sich demzufolge nachweislich um eine Verwechslung des „Todesengels von Auschwitz“ mit anderen SS-Ärzten. ${ }^{151}$ Was also die Ermittlung der Wahrheit in Entschädigungsverfahren betrifft, liegt im Umkehrschluss die Vermutung nahe, dass die Aussagen der Antragsteller oft unausweichlich Erinnerungsfehler enthalten mussten.

Die neuesten Forschungen im Bereich der Gedächtnis- und Erinnerungsgeschichte sind sich weitgehend einig, dass es die „wahre“ Erinnerung nicht geben kann. ${ }^{152}$ „Wir haben keinen inneren Lügendetektor. "So bringt der Sozialpsychologe Harald Welzer seine Theorie zur Erinnerung auf eine einfache Formel. In seiner Forschung zur Gedächtnisarbeit geht er davon aus, dass das, was wir erinnern, wenig mit der Vergangenheit zu tun hat. „Der Rückgriff in die Vergangenheit ist dafür da, dass wir uns in der Gegenwart orientieren." Folgt man dieser Argumentation, dann kann das Gedächtnis also keineswegs das verlässliche Archiv sein, für das wir es gerne halten, da keine objektiven Informationen und Erinnerungsbilder abgespeichert werden. Eindrücke werden ausgewählt, mit aktuellen Gegebenheiten ergänzt, neu geformt und zwar so, wie es für das Überleben in einer komplexen Welt nützlich ist. Lebensgeschichtliche Erfahrungen müssen also nicht auf eigene Erfahrungen zurückgehen, sondern können sich auch aus den Erzählungen anderer zusammensetzen.

Auch wenn diese Erkenntnisse damals noch nicht vorlagen, stellt sich die Frage, warum vielen Beamten in den Entschädigungsbehörden jegliches Verständnis dafür fehlte, dass die Angaben und die Erzählungen der Verfolgten gar nicht dazu geeignet sein konnten, die tatsächlichen Umstände vollständig wiederzugeben. Die Wiedergutmachung fand im bürokratischen Verfahren auf einer asymmetrischen Verhandlungsebene statt. Entsprechende Verhaltensweisen und "Spielregeln" schlichen sich auf beiden Seiten ein. Dazu zählten zum Beispiel „Lerneffekte“ unter den Verfolgten, die untereinander in Kontakt standen und Informationen über die jeweiligen Wiedergutmachungsverfahren austauschten. Unter Umständen wurde dann die eigene Geschichte so formatiert, dass sie in die Strukturen der Entschädigungsraster passte und der Verfahrensausgang erfolgversprechender schien. Eine Art Teufelskreis: Während der Verfolgte womöglich aus Mangel an aussagekräftigen Erinnerungen und stichhaltigen Unterlagen „unrichtige Aussagen“ als eine Form der legitimen Notwehr ansah, fühlte sich der Sachbearbeiter wiederum aufgerufen, diese „Lügen“ nachzuweisen und dem Antragsteller die Entschädigungsleistungen abzusprechen.

Gerade unter dem Gesichtspunkt der Verhältnismäßigkeit hätte widersprüchlichen Aussagen aber nur dann ein erheblicher Wert beigemessen werden dürfen, wenn sie dazu ge-

151 Zofka, KZ-Arzt Josef Mengele, S. 246.

152 Zur Erinnerungsforschung siehe Welzer, Das kommunikative Gedächtnis; außerdem die Publikationen von Alexander von Plato, zum Beispiel: Plato, Geschichte und Psychologie; ders., Zeitzeugen. Der Historiker Plato ist Gründungsdirektor des Instituts für Geschichte und Biographie in Lüdenscheid sowie Mitherausgeber und Redakteur der BIOS - Zeilschrift für Biographieforschung, Oral History und Lebensverlaufsanalysen. Eine Auseinandersetzung mit methodologischen und theoretischen Problemen findet man in Niethammer, Lebenserfahrung.

${ }^{153}$ Welzer, Das kommunikative Gedächtnis; siehe auch Martina Keller, „,Das ganze Leben ist eine Erfindung.' Harald Welzer hat nachgewiesen, wie wir unsere Erinnerung schönen. Jetzt erforscht er, wie das Gedächtnis entsteht.“, Die Zeit vom 18.3.2004. 
eignet gewesen wären, das Gesamtbild deutlich zu verändern. Dazu wäre jedoch die genaue Kenntnis der zeitlichen, örtlichen und sachlichen Verhältnisse, in denen sich die festzustellenden Tatbestände entwickelt hatten, unbedingte Voraussetzung für eine Überprüfung der Entschädigungsanträge gewesen. Stattdessen verließ sich das Bundesfinanzministerium auf das spärlich vorhandene Beweismaterial, das bestenfalls eine lückenhafte Rekonstruktion der bis dahin bekannten Verbrechensgeschichte zuließ, so dass es hinsichtlich der „Zweifelsfälle“ zu einer nennenswerten Zahl von Fehlentscheidungen kam.

Im Fall von Pierre D., der als Mitglied der Widerstandsbewegung in Frankreich verhaftet und in die Konzentrationslager Auschwitz, Buchenwald und Flossenbürg verbracht worden war, stellte der ärztliche Gutachter aufgrund der Folgen von Menschenversuchen in Auschwitz einen Grad der Erwerbsminderung von 90 Prozent fest. Den Angaben des Antragstellers zufolge hatte er Injektionen in Arme, Beine, Rücken und Bauch erhalten, außerdem seien an ihm Kälteversuche vorgenommen worden. Der zuständige deutsche Sachbearbeiter in Paris bestätigte dem Auswärtigen Amt, dass Pierre D. aufgrund seines Gesundheitszustands nicht berufstätig sei und daher auch kein Einkommen habe. ${ }^{154}$ Vier Monate später entschied das Bundesfinanzministerium, dass die Darstellungen von Pierre D. und das ärztliche Gutachten „keinerlei verwertbare Angaben über den Hergang des Versuchs“ enthalten hätten. ${ }^{155}$

Ähnlich erging es Herrn M., ebenfalls Mitglied der französischen Widerstandsbewegung, der im Konzentrationslager Struthof für Fleckfieberversuche missbraucht worden war und laut ärztlichem Gutachten als 75 Prozent erwerbsgemindert eingestuft wurde. ${ }^{156}$ Ein französischer Arzt, der ebenfalls in Struthof deportiert war, hatte die Angaben von Herrn M. zwar zusätzlich bestätigt, das Bundesfinanzministerium teilte dem Antragsteller jedoch mit, dass es sich bei den Injektionen vermutlich um vorbeugende Impfungen gegen Krankheiten gehandelt habe und daher nicht bewiesen sei, dass an Herrn M. Menschenversuche durchgeführt worden seien. ${ }^{157}$

Dagegen wurde mit den Tätern von deutscher Seite weit wohlwollender verfahren, wie der Fall von Otto Bickenbach beweist. Als Professor der Reichsuniversität Straßburg und Leiter der medizinischen Poliklinik hatte Bickenbach zur „Pathologie und Therapie der Kampfstofferkrankungen " geforscht. Im Konzentrationslager Natzweiler hatte sich die Gelegenheit geboten, die von ihm entwickelte Substanz gegen das Giftgas Phosgen an Häftlingen auszuprobieren. In Zusammenhang mit dem gegen ihn angestrengten Strafverfahren wurde von der Universität Bonn eigens ein 10-seitiges Gutachten über das Problem der „Pflichtenkollision“ erstellt.

Obwohl im Verlauf der von Bickenbach durchgeführten Versuchsreihen vier Menschen zu Tode gekommen waren, vertrat der für das Gutachten verantwortliche Sachverständige die These, dass der Arzt durch seine Mitwirkung die Gefährdung einer größeren Zahl von Versuchspersonen möglicherweise verhindert habe. Daher sei Bickenbach „auch unter Anlegung strenger ethischer Maßstäbe“ kein Vorwurf zu machen, da er das getan habe, „was wir auch bei rückschauender Betrachtung von einem gewissenhaften Arzt in dieser Lage

\footnotetext{
154 Diplomatische Vertretung der Bundesrepublik Deutschland in Paris an AA, 3.6. 1954, PA/AA, B $81 / 978$.

155 Blessin, BMF, an AA, 23. 10. 1954, PA/AA, B 81/978.

156 Diplomatische Vertretung der Bundesrepublik Deutschland in Paris an AA, 21.6.1954, PA/AA, B $81 / 978$.

157 BMF an den Antragsteller Frantz M., 30.11. 1955, PA/AA, B 81/978.
} 
erwarteten". 158 Bickenbach, der 1954 von einem französischen Gericht zu 20 Jahren Zwangsarbeit verurteilt worden war, kam im Herbst 1955 frei. Kurze Zeit später wurde er bereits von der Deutschen Forschungsgemeinschaft gefördert und beantragte zu seiner Rehabilitierung die Eröffnung eines berufsgerichtlichen Verfahrens. ${ }^{159}$

\section{Medizinische Gutachten und ärztliche Sachverständige im Entschädigungsverfahren}

Voraussetzung für eine Entschädigungsleistung nach dem Kabinettsbeschluss von 1951 war ein ärztlicher Befund, der dem Antragsteller den ursächlichen Zusammenhang zwischen der dauernden Gesundheitsschädigung und dem vorgenommenen Experiment attestierte. Da der überwiegende Teil der Betroffenen im Ausland lebte, mussten von den deutschen Auslandsvertretungen Vertrauensärzte als Sachverständige für Entschädigungsfälle benannt werden, und zwar auf Weisung des Bundesfinanzministeriums nach Möglichkeit im Ausland lebende deutsche Ärzte. ${ }^{160}$ In erster Instanz wurden praktische Ärzte als Gutachter eingesetzt, später wurden jedoch auch vielfach Psychiater hinzugezogen. Aus naheliegenden Gründen standen jedoch nur wenige unvoreingenommene Mediziner zur Verfügung, denen diese Tätigkeit unbedenklich anvertraut werden konnte. Die Bearbeitung von gesundheitlichen Verfolgungsschäden wurde zudem in Fachkreisen als „heißes Eisen“ angesehen, stellte man sich doch in den Dienst der rechtspolitischen Idee der Wiedergutmachung und geriet nur allzu leicht seitens der Verfolgten und der Behörden ins Schussfeld der Kritik.

Tatsächlich war die Gutachtertätigkeit in Entschädigungsverfahren für den medizinischen Sachverständigen keine leichte Aufgabe. Abgeschlossene Studien über die Manifestation von Verfolgungsleiden lagen noch nicht vor, so dass die Gutachter unter dem Druck der Notwendigkeit ohne wissenschaftliche Grundlagen zu Ergebnissen kommen mussten. So konnte der Grad einer an Sicherheit grenzenden Wahrscheinlichkeit des Zusammenhangs zwischen Verfolgung und Gesundheitsschaden medizinisch de facto kaum erbracht werden.

Angesichts dieser allgemein vorherrschenden Ratlosigkeit arbeitete der Interministerielle Ausschuss eine Reihe von Richtlinien für die Gutachtertätigkeit aus, die den Untersuchungshergang regeln und einen objektiven Befund garantieren sollten. Aufgabe des ärztlichen Sachverständigen war es, festzustellen, ob und inwieweit der Antragsteller in seiner körperlichen Integrität durch die Verfolgung beeinträchtigt worden war. Die ärztliche Stellungnahme durfte jedoch nicht auf Möglichkeiten aufbauen, sondern musste den ursächlichen Zusammenhang zwischen dem vorliegenden Gesundheitsschaden und dem im Konzentrationslager durchgeführten Menschenversuch mit überwiegender oder wenigstens genügender Wahrscheinlichkeit nachweisen. ${ }^{161}$ Gutachterlich mussten ferner die Frage, ob und in welchem Grad eine durch diese Schädigung bedingte Minderung der Erwerbsfähig-

158 Aus dem Gutachten H. von Webers, Rechtsprofessor an der Universität Bonn, als Anhang zu dem Vermerk vom 9.2. 1956, über das Gespräch zwischen Otto Bickenbach und Georg Blessin am 3.2.1956 im BMF, BA, B 126/61082.

159 Klee, Auschwitz, S. 378-388.

160 Runderlass vom 7.4.1951, BA, B 126/12553.

161 Runderlass vom 21.6. 1951, BA, B 126/12553. 
keit bestand, geklärt und die Möglichkeit einer Heilung oder Linderung der Beschwerden eingeschätzt sowie vermerkt werden. ${ }^{162}$

Die Entscheidung, ob im Einzelfall die Annahme eines unzulässigen Versuchs gerechtfertigt und der vorliegende Gesundheitsschaden entschädigungspflichtig sei, war jedoch nicht an den im vertrauensärztlichen Gutachten vertretenen Standpunkt gebunden, sondern lag ausschließlich in der Zuständigkeit von medizinischen Sachverständigen des Interministeriellen Ausschusses. Aus einem Tätigkeitsbericht des Bundesfinanzministeriums geht deutlich hervor, dass „die Zugehörigkeit von Ärzten in leitenden Stellungen aus dem Innenund Arbeitsministerium eine sachverständige Würdigung der auftauchenden medizinischen Fragen gewährleistet". ${ }^{163}$

Diese Verfahrensweise ist mit der umstrittenen Konzeption für die Beurteilung von Körper- und Gesundheitsschäden im Rahmen der Bundesentschädigungsgesetzgebung durchaus vergleichbar. Auch hier überprüften und beurteilten Sachverständige der Entschädigungsbehörden, meist Amtsärzte aus Bereichen des öffentlichen Gesundheitsdienstes, die Richtigkeit eines Gutachtens, ohne den Antragsteller je gesehen, geschweige denn untersucht zu haben. Trotzdem hatten sie einen größeren Einfluss auf die Entscheidungen der Wiedergutmachungsbehörden als die eigentlichen Gutachter, was erhebliche Verzerrungen - oft zu Ungunsten der Betroffenen - zur Folge hatte. So kritisierte Walter Ritter von Baeyer, einer der ersten deutschen Mediziner, der sich mit den psychischen Leiden von NS-Verfolgten auseinandersetzte, die Praxis ärztlicher Schreibtischentscheidungen und schrieb 1958: „In einer wissenschaftlich begründeten Weise nicht entscheidbar, nicht differenzierbar, sind in der Regel Entschädigungsfälle, die nur nach Aktenlage, ohne persönliche Untersuchung und Befragung des Opfers zu beurteilen sind."164

Nicht zu Unrecht wurde das Gesundheitsschadenverfahren nach der Bundesentschädigungsgesetzgebung, deren Regelungen auch bei der hier diskutierten Opfergruppe zur Anwendung kamen, als „Stiefkind der Entschädigung“ bezeichnet. ${ }^{165}$ Verglichen mit anderen Schadensarten war die Entschädigung für Körper- und Gesundheitsschäden weitaus komplizierter und blieb daher lückenhaft und unbefriedigend. Juristisches und medizinisches Kausaldenken mussten miteinander in Einklang gebracht werden, was nicht zuletzt zu einer „Verbürokratisierung“ der Gesundheitsschäden führte. Nachdem eine pauschalisierende Entschädigung im Sinne eines Schmerzensgeldes vom Gesetzgeber nicht vorgesehen war, wurde die Entschädigungsleistung nach dem Grundsatz der abstrakten Beurteilung der Erwerbsfähigkeit bemessen. ${ }^{166}$

Für die Begutachtungspraxis bedeutete dies, dass sämtliche Leiden des Antragstellers festgestellt werden mussten, wobei die Minderung der Erwerbsfähigkeit zunächst getrennt für jedes Leiden errechnet wurde. Ferner musste beurteilt werden, ob der Gesundheitsschaden durch die Verfolgung „verursacht" oder „wesentlich mitverursacht“ worden war. Zudem war eine Unterscheidung zwischen „anlagebedingt abgrenzbaren“ oder durch die Verfolgung gegebenenfalls „richtungsweisend verschlimmerten “ Leiden vorzunehmen. Die Gesamtminderung der Erwerbsfähigkeit wurde schließlich nach einem Berechnungsmaßstab der Beeinträchtigung der Leistungsfähigkeit, der sich am Sozialversicherungsrecht

162 BMF an AA, 3. 4. 1951, BA, B 126/12553.

163 Tätigkeitsbericht des BMF vom 27.11.1957, BA, B 126/61084.

164 Baeyer, Erlebnisreaktive Störungen, S. 2320.

165 Pross, Wiedergutmachung, S. 133.

160 Zorn, Festsetzung des Hundertsatzes. 
orientierte, in Prozentzahlen ausgedrückt und die Entschädigungsleistung entsprechend festgesetzt. ${ }^{167}$ Nicht das subjektiv erlittene Leid wurde also finanziell aufgewogen, sondern der Schaden, der den Berechtigten aktuell am Gclderwerb hinderte. Für die Opfer hingegen bedeutete diese Quantifizierung in Prozentzahlen eine unerträgliche Banalisierung und Abwertung ihres Verfolgungsschicksals.

Den spezifischen Erscheinungsformen der gesundheitlichen Spätschäden von NS-Verfolgten konnte man mit diesen Regelungen jedoch nur sehr bedingt gerecht werden. Der ärztliche Sachverständige stand vor der Aufgabe, aus einer Fülle von Bedingungen jene eigentlich wirksamen Faktoren zu bestimmen, die es allein verdienten, Ursachen genannt zu werden, um den vorliegenden Gesundheitsschaden nach bestimmten Kategorien zu differenzieren. Aus verschiedenen Stellungnahmen von Vertrauensärzten, die überlebende Opfer von Menschenversuchen zu begutachten hatten, geht hervor, dass es kaum möglich war, den unmittelbaren Bezug zwischen den seinerzeit vorgenommenen Experimenten und dem derzeitigen Gesundheitszustand des Untersuchten herzustellen.

So meldete das Generalkonsulat in Amsterdam in einem Schreiben an das Auswärtige Amt vom September 1951 erhebliche Schwierigkeiten, „weil die Folgen der Experimente sehr unterschiedlich sind und auch durch ärztliche Begutachtung nicht immer einwandfrei nachzuweisen sein werden ". ${ }^{168}$ Auch im Verlauf der Aktion änderte sich an dieser Problematik nichts Grundlegendes, denn knapp zwei Jahre später äußerte sich das Generalkonsulat in Montreal: „Ganz eindeutig von ärztlicher Seite bejaht worden ist der ursächliche Zusammenhang noch in keinem der hier abgeschlossenen Fälle. "169 Das Bundesfinanzministerium blieb jedoch unbeirrbar und forderte, dass die Gesundheitsfolgen der Experimente von den Gesundheitsschäden, die durch Lagerhaft oder Misshandlungen entstanden waren, unter allen Umständen gutachterlich zu isolieren seien. ${ }^{170}$

Problematisch war außerdem, dass eine entschädigungspflichtige Krankheit im Rechtssinne nur dann vorlag, wenn Beschwerden vorhanden waren, die die körperliche Leistungsfähigkeit direkt beeinträchtigten. Der Krankheitswert von erlebnisreaktiven seelischen Störungen wurde lange Zeit unterschätzt oder blieb in vielen Fällen völlig unbeachtet. So hätte außer Zweifel stehen müssen, dass sich die Gesundheitsschäden bei überlebenden Opfern von Menschenversuchen keineswegs nur organisch manifestieren. Infolge des Schocks durch die zwangsweise vorgenommenen Versuche an gesunden, teilweise sehr jungen Menschen waren die Leiden vielfach psychischer Art und äußerten sich in einer Veränderung der Grundeinstellung. Das unauslöschliche Siegel des Erlebten haftete den Betroffenen oft in Form von depressiven, misstrauischen oder ängstlichen Reaktionen an. $\mathrm{Zu}$ dem Gefühl der Ungerechtigkeit und Demütigung kamen nicht selten Komplexe, die durch Arbeitsunfähigkeit und den damit verbundenen sozialen Abstieg hervorgerufen wurden.

Besonders tragisch war das Schicksal der Opfer von Sterilisations- und Kastrationsexperimenten, die sich aufgrund der Tatsache, keine Kinder mehr haben zu können, nicht nur gedemütigt, sondern häufig auch heiratsunfähig und zu lebenslanger Einsamkeit verurteilt fühlten. Das Generalkonsulat in Amsterdam sah sich mit einer ganzen Reihe dieser Fälle

167 Niederschrift über die Medizinische Konferenz, in Göttingen vom 14./15. 1. 1958, Referat Dr. W. Meywalds: „Zur Berechnung der ,Beeinträchtigung“ der Erwerbsfähigkeit“, BA, B 126/9903.

168 Generalkonsulat Amsterdain an AA, 17.9. 1951, PA/AA, B 81/147.

169 Generalkonsulat Montreal an AA, 12.4.1953, PA/AA, B 81/147.

170 BMF an Generalkonsulat Montreal, 3.6. 1953, PA/AA, B 81/147. 
konfrontiert: „Unter den Antragstellerinnen befanden sich mehrere [...], die keine Ehe mehr eingehen können, weil ihre Unterleibsorgane durch die Auschwitzer Experimente völlig zerstört sind. "171 Obwohl die psychischen Schäden im Gegensatz zu den physischen Schäden bei den Betroffenen oft bei weitem schwerwiegender waren, wurde eine Vielzahl diesbezüglicher Anträge unter der Maßgabe „kein Gesundheitsschaden“ abschlägig beschieden. ${ }^{172}$

Der Historiker Christian Pross vertritt die These, die Behörden hätten sich ärztlicher Gutachter bedient, „die gemäß den Interessen des Fiskus nicht zu großzügig begutachteten “. ${ }^{173}$ Er räumt allerdings ein, dass dies insbesondere für die Vertrauensärzte der Behörden im Inland galt und weniger für die Vertrauensärzte der deutschen Auslandsvertretungen. Im Fall der überlebenden Opfer von Menschenversuchen wurde den Anträgen der Betroffenen, bestimmte, auch medizinisch maßgebliche Sachverständige im Ausland einzuschalten, meist gar nicht erst stattgegeben. Der untersuchende Arzt musste noch nicht einmal die Zustimmung des Antragstellers finden, da „eine solche Mitwirkung des Patienten bei der Auswahl des Arztes mit der Objektivität, die vom Arzt erwartet wird, nicht vereinbar sei“. 174

Zwar hatte ein Vertreter der Vereinten Nationen nachdrücklich empfohlen, die Vertrauensärzte durch die zuständigen Stellen der betroffenen Länder vorschlagen zu lassen, da nur auf diese Weise der Eindruck der Parteilichkeit vermieden werden könne. ${ }^{175}$ Das Bundesfinanzministerium blieb von diesem Hinweis jedoch unbeeindruckt. So wurde ausgerechnet ein Beamter des Bundesgesundheitsamts nach Israel entsandt, obwohl auch das Auswärtige Amt aus psychologischen und politischen Gründen dringend von deutschen Gutachtern abgeraten hatte. ${ }^{176}$ Dass es in Kreisen der israelischen Betroffenen und ihrer Interessenvertreter hieß, ,jetzt schickt man uns einen Arzt, der der gleichen Nation angehört, die uns fast zu Tode gequält hat ${ }^{\text {"177 }}$, nahmen die Verantwortlichen in Bonn in Kauf.

Gutachten von ausländischen Ärzten schickten die Prüfärzte der deutschen Entschädigungsbehörden häufig mit dem Vermerk zurück, sie entsprächen nicht dem geforderten Standard. In diesen Fällen wurde entweder ein Zweitgutachten verlangt oder sofort eine Zurückweisung des Antrags empfohlen. Emigrierte Ärzte, die nach dem Zweiten Weltkrieg als Gutachter in Wiedergutmachungsverfahren tätig waren, mussten erfahren, dass ihre Stellungnahmen zu den Haftfolgen meist von den deutschen Kollegen verworfen wurden und den Gutachten der Vorzug gegeben wurde, die sich nicht an neue psychiatrische Erkenntnisse hielten oder ihre Urteile in Widerspruch zu diesen erstellten. ${ }^{178}$ „Viele der in Deutschland tätigen Gutachter waren frühere Nazis, wie ich ziemlich sicher bin; aber das konnte ich in meinen Gutachten nicht sagen, sonst wären eben meine Gutachten für die Überlebenden von den deutschen Gerichten (deren Richter vielfach auch alte Nazis wa-

171 Generalkonsulat Amsterdam an AA, 17.9.1951, PA/AA, B 81/147.

172 Tabellarische Liste über die Beurteilung von 151 Anträgen, o. D., BA, B 126/61084.

173 Pross, Wiedergutmachung, S. 139.

174 BMF an AA, 3.4. 1952, BA, B 126/12553.

175 Aufzeichnung Biermanns, AA, vom 25.4.1952, über den Besuch eines Vertreters der Vereinten Nationen in Bonn, PA/AA, Abt. II, Bd. 1664.

${ }^{176} \mathrm{AA}$ an BMF, 12.8.1953, PA/AA, Abt. II, Bd. 1664.

177 Aufzeichnung Jochen Abraham Froweins, AA, vom 24.6. 1953, über Unterredung Froweins mit Dr. Yahil am 22.6.1953, PA/AA, Abt.II, Bd.1664.

${ }^{178}$ Leibfried, Berufsverbote, S. 170. 
ren) glatt abgelehnt worden“, schrieb der international anerkannte Psychoanalytiker William G. Niederland. ${ }^{179}$

Aktenkundig wurde der Fall des deutschen Vertrauensarztes Dr. H., der für die Deutsche Botschaft in Paris als Gutachter in Wiedergutmachungsangelegenheiten tätig war. In einem fünfseitigen Schreiben ersuchte die deutsche Auslandsvertretung das Auswärtige Amt in Bonn, Dr. H. von dieser Aufgabe zu entbinden, da es „der Botschaft schlechterdings nicht mehr möglich [ist], mit einem Manne zusammenzuarbeiten, der bereits vor mehreren Jahren die Schreibkräfte des Wiedergutmachungsreferats in einem Schreiben an die Botschaft verleumdete und der ständig seine französischen jüdischen Arztkollegen in den Augen der Botschaft und der Entschädigungsorgane herabzusetzen und zu disqualifizieren bestrebt ist". ${ }^{180}$

Belegt sind ferner die Klagen von Verfolgten über den medizinischen Gutachter der Deutschen Botschaft in Chile. Eingehende Nachprüfungen des Entschädigungsamts Berlin ergaben schließlich, dass die Proteste berechtigt waren. Tatsächlich war Dr. Gerber, der Mitglied der NSDAP und des nationalsozialistischen Ärztebundes gewesen war, für die Begutachtung von Verfolgten denkbar ungeeignet. In allen geprüften Fällen musste von der Berliner Entschädigungsbehörde eine Änderung des Gutachtens zugunsten des Antragstellers vorgenommen werden, da „Herr Dr. G. wesentliche Umstände außer Acht gelassen hat" und in keinem Fall eine verfolgungsbedingte Beeinträchtigung feststellte. ${ }^{181}$

Auch der mit Wiedergutmachungsangelegenheiten befasste amerikanische Rechtsanwalt Erich Cohn bemängelte in einem Schreiben an das Bundesfinanzministerium, dass das Deutsche Generalkonsulat in New York „kaum Psychiater findet, die ihrer Aufgabe als Vertrauensärzte gewachsen sind“. Konkret kritisierte er Dr. W., „der jetzt annähernd 10 mal hintereinander in von mir vertretenen Sachen falsche Gutachten gemacht hat" und der „auch auf die unsinnigsten Verlangen der deutschen Amtsärzte sofort sein Gutachten zum Nachteil der Verfolgten abändert". ${ }^{182}$

Sieht man die einschlägigen Akten der Finanzbehörde ein, so drängt sich die Vermutung auf, dass die ohnehin wenigen Gutachter, die als anerkennungsfreudig galten, regelrecht ausgeschaltet werden sollten. So sorgte die vehemente Kritik eines schwedischen Arztes, der vom Deutschen Generalkonsulat in Göteborg mit der Begutachtung von Verfolgten beauftragt worden war und dessen Kompetenzen von der zuständigen deutschen Entschädigungsbehörde unbotmäßig in Zweifel gezogen worden waren, für einigen Wirbel. In einem Schreiben an die Landesrentenbehörde Nordrhein-Westfalen vom 18.Juli 1965 verwehrte sich dieser Dr. H. gegen deren in diesem Zusammenhang völlig unsachliche Bemerkung, dass in Schweden „Abtreibungen sehr leicht und keineswegs nur aus medizinischer Indikation" vorgenommen würden. In dem Schreiben des schwedischen Gutachters hieß es weiter: „Wenn dieser Ausdruck und diese jämmerliche sog. ,Beweisführung“ nicht umgehend zurückgenommen wird, werde ich die Angelegenheit an das schwedische Gesundheitsministerium weitergehen lassen. Ich kann nicht zulassen, dass mein Patient als NS-Verfolgter und außerdem auch das schwedische Medizinalwesen auf diese unflätige Art be-

${ }^{179}$ Brief vom 26. 1. 1988, zit. nach Focke, Psychiater der Verfolgten, S. 97.

180 Aufzeichnung über die in viclerlei Hinsicht problematische Zusammenarbeit mit dem Vertrauensarzt Prof. Dr. H., Botschaft Paris an AA, 28.8. 1964, PA/AA, B 81/161.

181 Entschädigungsamt Berlin an Landesamt für Wiedergutmachung und verwaltete Vermögen Rheinland-Pfalz, 14.11.1956, PA/AA, B 81/322.

182 Dr. Cohn an Ministerialdirektor Zorn, BMF, 1.9. 1964, PA/AA, B 81/323. 
schimpft werden, und daneben meine Beweisführung völlig übersehen wird, die sich auf die bekannten Spätfolgen des Typhus stützt, die seinerseits kausal mit der Verfolgung zusammenhängen. " 183

Die deutsche Vertretung in Göteborg, die bereits darauf hingewiesen hatte, dass nicht genügend geeignete Gutachter zur Verfügung ständen, reagierte auf die Forderung der deutschen Behörden, Dr. H. vor dem Hintergrund des geradezu peinlichen Vorfalls nicht mehr als Gutachter zu beauftragen, mit Entsetzen: „Bei dem großen Interesse, das die schwedische Öffentlichkeit gerade Fragen der Wiedergutmachung entgegenbringt, kann deren negative Wirkung nicht hoch genug eingeschätzt werden. "184 Die Landesrentenbehörde sah sich nun zum Einlenken gezwungen. Das vierzeilige Schreiben, in dem Dr. H. offiziell um Entschuldigung gebeten wurde, hätte allerdings nicht knapper ausfallen können. ${ }^{185}$

Dass es sich hier nicht um eine Ausnahme handelte, zeigt ein weiterer Fall. Dem Vertrauensarzt des Generalkonsulats in London, der über langjährige Erfahrung als Sachverständiger beim High Court of Justice verfügte, wurde „Unzulänglichkeit“ in seiner Arbeit als Begutachter von Verfolgten vorgeworfen. ${ }^{186}$ Mit dem Hinweis, dass nicht ausschließlich die organischen Schäden, sondern mindestens ebenso stark die psychischen Folgen der vorgenommenen Experimente zu berücksichtigen seien, hatte der Arzt den Gesundheitsschaden bei einem Großteil der untersuchten Antragsteller als „entschädigungspflichtig“ eingestuft. ${ }^{187}$ Das Bundesfinanzministerium ließ diese Auffassung nicht gelten und forderte eine Nachprüfung durch einen Spezialarzt. ${ }^{188}$

In anderen Fällen wurde die Einholung eines zweiten Gutachtens jedoch strikt abgelehnt, da man Revisionsfälle befürchtete. So war bei 37 von 40 untersuchten Antragstellern in Schweden vom zuständigen medizinischen Sachverständigen ein Gesundheitsschaden aufgrund von Humanexperimenten verneint worden. Nachdem bekannt geworden war, dass die Betroffenen die Absicht hatten, gegen den verantwortlichen Arzt eine Klage anzustrengen, sprach sich das Generalkonsulat in Stockholm dafür aus, einen anderen Arzt mit einer zweiten Begutachtung zu beauftragen. ${ }^{189}$ Bundesfinanz- und Bundesinnenministerium wiesen diesen Vorschlag jedoch übereinstimmend ab, da ansonsten „in Zukunft mit gutem Grund auch von den übrigen Personen; bei denen Beihilfeanträge abgelehnt wurden, die Durchführung einer erneuten ärztlichen Untersuchung verlangt werden kann". 190

In den 1980er Jahren begann die Auseinandersetzung mit der medizinischen Wissenschaft und ihrer Vergangenheit auf verschiedenen Ebenen. Im selben Zeitraum erschienen auch einige Studien, die sich mit der Wiedergutmachung bei Schäden an Körper und Ge-

183 Dr. H. an die Landesrentenbehörde Nordrhein-Westfalen, 18. 7. 1965, PA/AA, B 86/1321.

184 Dr. Stoecker, Generalkonsulat Stockholm, an AA, 18. 7. 1965, PA/AA, B 86/1321.

${ }^{185}$ Landesrentenbehörde Nordrhein-Westfalen an Dr. Haché, 13.8. 1965, PA/AA, B 86/1321.

186 Interne Stellungnahme zur Auswahl des Vertrauensarztes, BMF, Schmidt an Biella, 30.3. 1954, BA, B $126 / 12553$.

187 Stellungnahme Dr. S.s zu den Beanstandungen des Interministeriellen Ausschusses vom 26.5. 1952, Generalkonsulat London an AA, 27.5.1952, BA, B 126/12554.

188 BMF an AA, 12.5.1952, BA, B 126/12554.

189 „In der Sitzung vom 27.3. 1954 kündigte Herr Jesser vom Auswärtigen Amt an, daß die abgewiesenen Antragsteller in Schweden die Absicht hätten, gegen den Vertrauensarzt [...] Klage zu erheben." Aus einer internen Stellungnahme zur Auswahl des Vertrauensarztes, BMF, Schmidt an Biella, 30.3. 1954, BA, B 126/12553.

190 BMI an BMF, 23.9. 1954, BA, B 126/12554. 
sundheit beschäftigten und „einhellig“ zu dem Ergebnis kamen, dass insbesondere die deutschen Behörden und Vertrauensärzte, die in Entschädigungsangelegenheiten eine außerordentliche Verantwortung trugen, ihrer Aufgabe oft nicht gerecht wurden. ${ }^{191}$ Wie die große Zahl ärztlicher Fehlentscheidungen bei der Begutachtung von Verfolgten zu beurteilen ist, hängt unmittelbar mit der Frage zusammen, warum die Ansichten der auf diesem Gebiet tätigen Personen so häufig und in einem nicht tolerierbaren Maße voneinander abwichen. Es ist nicht zu übersehen, dass die Diagnosen weitgehend von der persönlichen Disposition des jeweiligen Gutachters abhingen. Nicht zu unterschätzen ist außerdem, dass - wie in vielen anderen gesellschaftlichen Bereichen - die zentralen Denkmuster der nationalsozialistischen Weltanschauung auch in der medizinischen Wissenschaft nicht sofort verschwanden.

Eine wesentliche Ursache für das mangelnde Engagement innerhalb der bundesdeutschen Ärzteschaft bei der Begutachtung von NS-Verfolgten ist in der personellen Kontinuität und in der Voreingenommenheit gegenüber neuen wissenschaftlichen Erkenntnissen aus dem Ausland zu sehen. „Die Deutschen haben es nach 1945 nicht verstanden, den Nationalsozialismus und seine Folgen aufzuarbeiten, und das gilt insbesondere von der Mehrzahl der deutschen Ärzte zusammen mit ihren Standesvertretern."192 Dass sich die Mentalität der in Deutschland verbliebenen Ärzte nach dem Zweiten Weltkrieg nicht verändert habe, konstatierten emigrierte jüdische Kollegen im Rahmen des Berliner Gesundheitstages noch im Jahr 1980. Die Tabuisierung dieses dunklen Kapitels deutscher Medizingeschichte lebte in großen Teilen der Ärzteschaft fort, und die üblichen Abwehrmechanismen wie Verdrängung, Verhüllung und Verleugnung unangenehmer Wahrheiten spiegeln sich unweigerlich auch in der Wiedergutmachung. Im Extremfall trafen die Antragsteller auf Gutachter, die als Täter, Mittäter oder Mitwisser des begangenen Unrechts ein weit größeres Interesse hatten, die Spuren der Verfolgung zu verwischen, als Gesundheitsschäden dem internationalen Erkenntnisstand entsprechend als „verfolgungsbedingt“ anzuerkennen. ${ }^{193}$

Weil sich die Ärzteschaft nicht mit ihrer Vergangenheit auseinandersetzte, wurde ihr auch nicht bewusst, dass durch die Ausgrenzung, Vertreibung und Verfolgung jüdischer Ärzte und durch die Emigration wichtiger Fachleute eine große Lücke in der medizinischen Wissenschaft entstanden war. So kommt der kanadische Historiker Michael Kater zu dem Ergebnis, dass „das Dritte Reich den Rahmen für die vorläufige Entprofessionalisierung der Medizin in Deutschland“ bildete. ${ }^{194}$ Seitens der deutschen Ärzte standen daher kaum qualifizierte Personen für die Begutachtung von Verfolgten zur Verfügung. In der Wieder-

191 Siehe Niederland, Folgen der Verfolgung; ders., Dic verkannten Opfer; das Kapitel „Schaden an Körper und Gesundheit“, in: Pross, Wiedergutmachung, S. 131-266; Fischer-Hübner (Hrsg.), Kehrseite der „Wiedergutmachung“.

192 Diskussion mit den beiden emigrierten Berliner Ärzten Prof. Otto Löwenstein und Prof. Erich Simenauer in der Freien Universität Berlin im Rahmen des Gesundheitstages, vgl. Leibfried, Berufsverbote, S. 170 u. S. 178.

193 Zum Beispiel im Fall des international gesuchten Prof. Dr. Werner Heyde, der unter dem Decknamen Dr. Fritz Sawade als Sachverständiger für das Oberversicherungsamt Schleswig in Renten- und Wiedergutmachungsangelegenheiten Gutachten ausstellte, vgl. Scharffenberg, Sieg der Sparsamkeit, S.101f; bekannt wurde auch der Fall des ehemaligen SS-Untersturmführers Heinrich Berning. Der Internist, der an sowjetischen Kriegsgefangenen Hunger-Experimente zur Ernährungsforschung durchgeführt hatte, wurde nach 1945 nicht nur Chefarzt in einem Krankenhaus, sondern auch Hauptgutachter eines Wiedergutmachungsamts, vgl. Otto, Wehrmacht, S. 79; sowie Klee, Personenlexikon, S. 43 .

194 Kater, Medizin und Mediziner, S. 352. 
gutmachung spielten die fehlende Sachkenntnis der deutschen Gutachter, ihre Einstellung und ihre wissenschaftliche Orientierung bedauerlicherweise eine nicht unerhebliche Rolle. In vielen Fällen wurden die verfolgungsbedingten Gesundheitsschäden nicht in angemessener Weise diagnostiziert und - was für die Betroffenen fatale Folgen haben konnte auch nicht entsprechend therapiert.

Die ärztliche Gutachtertätigkeit in Entschädigungsverfahren fand gerade in den Anfangszeiten unter denkbar ungünstigen Voraussetzungen statt. Über die Dimension und die inneren Zusammenhänge von Verfolgung und spezifischen Spätschäden bestanden in der wissenschaftlichen Theorie und in der ärztlichen Praxis noch keine ausreichenden und allgemein verbindlichen Kenntnisse. Nach 1945 befasste sich die deutsche Ärzteschaft zwar mit den Erkrankungen der Kriegsopfer und Kriegsgefangenen; die Leiden derer, die in den Konzentrationslagern überlebt hatten, fanden jedoch vergleichsweise wenig wissenschaftliches Interesse. Das Gebiet der Verfolgungskrankheiten war in Deutschland nur unzureichend erforscht und blieb lange „terra incognita“. Mangelnde ärztliche Kompetenz und die daraus resultierende Unsicherheit im Umgang mit der Begutachtung von Verfolgten waren die Folge.

Die Leiden der Verfolgungsopfer wurden meist kritiklos mit Beobachtungen bei Unfallund Kriegsfolgeschäden gleichgesetzt, obwohl die unmittelbare Übertragung versorgungsrechtlicher Maßstäbe den spezifischen Gesundheitsschäden der KZ-Überlebenden keineswegs gerecht wurde. Gerade die deutsche Psychiatrie sträubte sich hartnäckig, ihre veralteten Vorstellungen aufzugeben. Seit 1926 galt in Deutschland eine Grundsatzentscheidung des Reichsversicherungsamts über die „medizinische und rechtliche Bedeutung von traumatischen Neurosen“, wonach eine Neurose als Unfallfolge nicht rentenpflichtig sei, da die Ausgleichsfähigkeit des Organismus nach psychischen Belastungen praktisch unbegrenzt und damit eine dauerhafte Erwerbsminderung durch eine Unfallneurose nicht möglich sei. $^{195}$

Den Erfahrungshorizont für die Begutachtung von gesundheitlichen Schädigungen bei Verfolgten bildete hier vor allem der allgemeine medizinische Wissensstand im Zusammenhang mit der Behandlung von sogenannten Kriegsneurotikern aus dem Ersten Weltkrieg. Anhand der als „Kriegszitterer“ oder „Schüttler“ stigmatisierten Opfer, denen Feigheit vor dem Feind nicht zuletzt aufgrund einer anlagebedingten schwachen und demzufolge minderwertigen Disposition unterstellt wurde, hatte sich ein Menschenbild geformt, dass auch in der Folge die Auslese der Nutzlosen zugunsten der Tapferen propagierte. Sogar führende Wissenschaftler dieser Zeit sprachen von einer regelrechten „Entartung“ der Kriegsneurotiker, die - wenn überhaupt - nur durch drastische Methoden von ihrem Simulantentum geheilt werden könnten. Über Jahrzehnte wurde diesen traumatisierten Soldaten weder Verständnis entgegengebracht noch eine entsprechende Therapie zuteil. ${ }^{196}$

Eine Reihe namhafter deutscher Wissenschaftler hielt auch noch Jahre nach dem Zweiten Weltkrieg an der Auffassung fest, dass seelische Belastungen und Erschütterungen, gleich welcher Art, nach dem Ende der Verfolgung abklingen und keinen Krankheitswert im versorgungsrechtlichen Sinn darstellen, von Dauerfolgen und Spätschäden ganz zu

\footnotetext{
195 Vgl. das Kapitel „Die herrschende medizinische Lehrmeinung in der Bundesrepublik“, in: Pross, Wiedergutmachung, S. 149-160, hier S. 152.

196 Zur Problematik der Kriegsneurotiker nach dem Ersten Weltkrieg vgl. den Beitrag des Heidelberger Medizinhistorikers Wolfgang Eckart im Rahmen eines Sammelbands zur historischen Traumaforschung: Eckart, Kriegsgewalt und Psychotrauma.
} 
schweigen. ${ }^{197}$ „Von einer Tiefenwirkung und Weiterwirkung der stattgehabten Verfolgungsmaßnahmen - von Ächtung, Diskriminierung, Diffamierung, Erniedrigung, Verfemung, Vertreibung aus Amt und Würde, um nur einige auf seelischem Gebiet zu nennen - war höchst selten die Rede. "198 Abnorme seelische Reaktionen auf Kriegserlebnisse wurden nach herrschender Lehrmeinung als „Begehrensvorstellungen“ mit dem Ziel einer Rente gewertet. Die Therapie der „Rentenneurose“ bestand in der Nichtgewährung einer Rente. Da das gesamte Versicherungs- und Versorgungswesen von dieser Theorie durchdrungen war, wurden die psychisch zerstörenden Folgen der NS-Verfolgung aus Angst vor einer Flut von „Entschädigungsneurosen“ abgestritten oder vielfach pauschal mit tendenziösen „Rentenneurosen“ gleichgesetzt. Die Vorstellung, dass bei fehlendem Organbefund kein Gesundheitsschaden vorliege, führte nicht selten dazu, dass Antragsteller - und hier wird die Parallele zur Einschätzung des Krankheitsbilds bei Kriegsneurotikern deutlich - als Simulanten abgestempelt wurden.

Eine weitere Ursache für falsche Beurteilungen war die Tatsache, dass sich die ärztlichen Sachverständigen von amtlichen Merkblättern in der Begutachtungspraxis instruieren ließen, nach denen bestimmte Krankheitsformen grundsätzlich nicht als verfolgungsbedingt angesehen werden sollten oder keinen „Krankheitswert“ hatten. ${ }^{199}$ Die besondere Eigenart der Verfolgungsschäden gestattete jedoch keineswegs die sinngemäße Anwendung wissenschaftlicher Lehrsätze aus anderen medizinischen Gebieten. Infolge der lückenhaften Grundlagenforschung wurde die Bedeutung des Erb- und Anlagefaktors bei der Begutachtung von NS-Verfolgten oft überschätzt, was zu einer ständigen Herabminderung, Verharmlosung oder gar Leugnung der Beschwerden führte. Immer wieder findet man daher in ablehnenden Gutachten Formulierungen wie „anlagebedingtes“, „altersbedingtes“ oder „schicksalsbedingtes“ Leiden, an denen sich die Tendenz deutscher Gutachter, selbst schwere Gesundheitsschäden zu bagatellisieren, ablesen lässt. ${ }^{200}$

Problematisch war ferner, dass der Zusammenhang zwischen Verfolgung und Gesundheitsschaden als umso fragwürdiger angesehen wurde, je weiter diese auseinander lagen. Demzufolge wurde die Verfolgungsbedingtheit einer Krankheit mit zunehmendem Abstand vom Zeitpunkt der Befreiung geringer eingestuft. ${ }^{201}$ So zeugt es von einem unglaublichen $\mathrm{Ma}$ an Verständnislosigkeit, wenn der Vertrauensarzt den Gesundheitszustand eines französischen Antragstellers, der im Konzentrationslager Dachau Opfer von Typhusexperimenten geworden war, acht Jahre später als „leidlich gut“ und demzufolge als „nicht entschädigungspflichtig“" bezeichnete. Tatsächlich hatte der Betroffene nach eigenen Angaben alles Erdenkliche getan und keine Kosten gescheut, um die schrecklichen Folgen der Versuche zu überwinden und monierte zu Recht, „ob dieser Arzt erwartet habe, ein Skelett vorzufinden, als das er Dachau 1945 verlassen habe“. ${ }^{202}$

197 Ebd.

198 Niederland, Folgen der Verfolgung, S.7f:

199 So etwa von den Anhaltspunkten für ärztliche Gutachtertätigkeit im Versorgungswesen, zusammengestellt von der Ärztlichen Abteilung des Bundesministeriums für Arbeit, Bonn 1954.

200 Auch Scharffenberg kommt bei den von ihm ausgewerteten Fällen zu diesem Ergebnis. Die am häufigsten verwendete Begründung für das Verneinen des Kausalzusammenhanges zwischen Haft und Leiden war die, dass es sich bei dem betreffenden Schaden um „anlagebedingte“ Leiden handle, vgl. Scharffenberg, Sieg der Sparsamkeit, S. 95.

201 Matussek, Konzentrationslagerhaft, S. 70.

${ }^{202}$ Aus dem Brief eines Antragstellers, übermittelt vom Generalkonsulat Montreal, an AA, 12.4. 1953, PA/AA, B 81/147. 
Die deutschen Gutachter erwarteten vom Antragsteller eine naturwissenschaftlich nachvollziehbare Kausalkette seiner Krankheitsgeschichte. Zum Nachweis eines Verfolgungsleidens mussten sogenannte Brückensymptome vorliegen. Durch Vorlage von Attesten musste der Betroffene belegen, dass Anzeichen für sein Leiden gleich im Anschluss an die Verfolgung aufgetreten waren und über die Jahre bis zum Zeitpunkt der Begutachtung fortbestanden hatten. Dass viele Gesundheitsschadensfälle an fehlenden „Brückensymptomen“ gescheitert sind, unterstreicht, wie ausgesprochen fragwürdig teilweise begutachtet wurde. Zum einen existierten in der besagten Zeit keine zuverlässigen Untersuchungsmöglichkeiten. Daher konnten auch keine Nachweise für ärztliche Behandlungen während und nach der Verfolgung erbracht werden. Zum anderen widerspricht die Forderung nach „Brückensymptomen“ insbesondere auf dem psychiatrischen Gebiet allen wissenschaftlichen Erkenntnissen.

Was das Auftreten seelischer und psychosomatischer Reaktionsweisen nach dem Ende der Verfolgung angeht, so ist erwiesen, dass diesen Störungen eine Monate bis oft Jahre dauernde Latenzperiode vorangehen kann. Die erlebnisreaktive Symptomatik blieb zunächst meist diskret und brach beispielsweise erst Jahre nach der Ankunft im Einwanderungsland in Form schwerer Anpassungskrisen auf. Daher ist die These psychiatrisch unhaltbar, dass die Neurosen der Verfolgten oft nur angesichts der Existenzschwierigkeiten im Ausland entstanden seien. ${ }^{203}$ Vielmehr setzten viele Überlebende des Holocaust nach dem Krieg meist alles daran, ihre Erlebnisse so schnell wie möglich zu verdrängen, um ein neues Leben $\mathrm{zu}$ beginnen ${ }^{204}$ - auch wenn sich diese Haltung in den folgenden Jahre oft als psychologische Hypothek erweisen sollte, denn die Kehrseite der Verdrängung war die Wiederkehr der seelischen Beeinträchtigungen. „Da war ein Leid, dessen Tiefe proportional zur Tiefe und Größe der Erinnerung wuchs, proportional zur zeitlichen Distanz." 205

Die ignorante Haltung der deutschen Mediziner gegenüber den Leiden der Verfolgten wurde durch die deutsche Rechtsprechung noch gefördert. So war in einem Grundsatzurteil entschieden worden, dass bei Differenzen zwischen ausländischen und deutschen Ärzten der in Deutschland vorherrschenden Lehrmeinung zu folgen sei, da anderenfalls keine gleichmäßige Behandlung aller Verfolgten gewährleistet sei. ${ }^{206}$ Wegweisenden wissenschaftlichen Untersuchungen aus dem Ausland wurde somit nicht die erforderliche Beachtung geschenkt und die Meinung ausländischer Ärzte nicht akzeptiert. ${ }^{207}$ Gerade auf dem psychiatrischen Gebiet stellte die NS-Vergangenheit eine schwere Hypothek für die Reformbewegung dar, denn „die Psychiater haben sich nach dem Krieg wegen der NS-Ver-

203 Matussek, Konzentrationslagerhaft, S. $78 f$.

${ }^{204}$ Eine Beschreibung der verschiedenen Strategien des Umgangs mit der Erinnerung liefert Segall, Konzentrationslagererlebnisse, S.221.

205 Focke, Psychiater der Verfolgten, S. 29.

206 Grundsatzentscheidung vom 30.5.1969, 17 U Entsch. 1269/67, in: RzW 10/11 (1969), S. 473.

207 In Frankreich, Dänemark, Norwegen und Holland war bereits zwischen 1946 und 1950 entsprechendes Material gesammelt und untersucht worden. In Kopenhagen fand die „Internationale Sozialmedizinische Konferenz über die Pathologie der ehemaligen Deportierten und Internierten vom 5. bis 7. Juni 1954" statt. Die Ergebnisse wurden der Bundesrepublik Deutschland offiziell zugänglich gemacht. Vgl. dazu Focke, Psychiater der Verfolgten, S.125. Ferner sei in diesem Zusammenhang auf folgende wissenschaftliche Veröffentlichungen aus dem Ausland verwiesen: Fichez, Asthenie; ders./ Klotz, Die vorzeitige Vergreisung; Eitinger, Concentration Camp Survivors; Krystal (Hrsg.), Massive Psychic Trauma. 
brechen hinter ihre Mauern zurückgezogen“. ${ }^{208}$ Auf der anderen Seite gab gerade die Wiedergutmachung die notwendigen Impulse, um den Reformprozess in Gang zu setzen. Im Verlauf der Entschädigungsverfahren entstand, wie es die Autorin Helen Epstein treffend formulierte, „eine eigene Zunft von Psychiatern“.209

Einer der ersten, der die Frage nach der Belastbarkeit der menschlichen Psyche nach extremen Verfolgungsereignissen unter einem anderen Blickwinkel erforschte, war der deutsch-amerikanische Psychiater William Niederland. Als Gutachter und Obergutachter untersuchte er im Rahmen von Wiedergutmachungsverfahren in den 1960er Jahren fast $1000 \mathrm{KZ}-$ Überlebende und prägte den Begriff des „Überlebenden-Syndroms“.210 „Das ist keine Depression, das ist ein neues Krankheitsbild: Survivor-Syndrom. Die Krankheit der Überlebenden im doppelten Sinne. Die Leute leiden chronisch an Schuldgefühlen oder der nicht überwundenen Verfolgung, oder die Krankheit ist eine Folge des nicht überwundenen Konzentrationslager-Traumas. “211

Auch in Deutschland erschienen erste Arbeiten von Außenseitern der Fachwelt, die den Rahmen der herrschenden Lehrmeinung sprengten und das traditionelle Begutachtungsverfahren in Frage stellten. Bereits 1953 publizierte der Psychiater Ulrich Venzlaff eine Studie, in der er auf der Grundlage von Untersuchungen an NS-Verfolgten den Begriff des „erlebnisbedingten Persönlichkeitswandels“ einführte und dieses psychische Leiden als wiedergutmachungspflichtig einstufte. ${ }^{212}$ Eine Reihe junger „aufmüpfiger“ Oberärzte setzte sich nicht nur dafür ein, die menschenunwürdigen Zustände in den psychiatrischen Anstalten zu verändern, sondern versuchte gleichzeitig die „Schuld der Väter“ abzutragen.

Der mittlerweile öffentlich ausgefochtene Streit um die Anerkennung psychischer Verfolgungsschäden erhielt durch die Veröffentlichung eines Sammelbands mit dem Titel „Psychische Spätschäden nach politischer Verfolgung“ im Jahr 1963 neuen Zündstoff. ${ }^{213}$ Darin hatten die Vertreter der "Neuen Lehrmeinung“ - unter ihnen die Herausgeber Hans-Joachim Herberg und Helmut Paul - anhand gezielter Studien bei der Begutachtung von Verfolgten völlig neue, in der deutschen Wissenschaft bis dahin unerforschte Krankheitsbilder ohne zweck- und wunschbedingte Färbung gefunden und damit einen Gutachterstreit ausgelöst, der nicht nur zwischen ausländischen und deutschen Sachverständigen, sondern auch im eigenen Lager ausgetragen wurde. ${ }^{214}$

Ein Jahr später griffen der Psychiater Walter Ritter von Baeyer und seine Kollegen Karl Peter Kisker und Heinz Häfner das Thema auf. Unter dem Titel „Psychiatrie der Verfolgten“ publizierten sie eine Untersuchung über die psychopathologischen und gutachterlichen Erfahrungen mit NS-Verfolgten und zeigten auf, dass seelische Extrembelastungen auch ohne körperliche Schädigung krankhafte seelische Dauerfolgen bewirken können. ${ }^{215}$ Zwar

208 Diese Feststellung traf der Heidelberger Psychiatrieprofessor Heinz Häfner, der als stellvertretender Vorsitzender der Enquete-Kommission, die 1971 vom Deutschen Bundestag eingesetzt wurde, die Psychiatriereform von 1975 unterstützte. Im Vergleich zu den USA und zu Großbritannien setzte die Reformbewegung in Deutschland erst 20 Jahre später als Folge der "gesellschaftlichen Hochdruckzone der 1968er" ein. Siehe dazu Bühring, Psychiatrie-Geschichte: Wendepunkt 1968.

209 Epstein, Kinder des Holocaust, S. 92.

210 Vgl. dazu Focke, Psychiater der Verfolgten.

211 Zit. nach Focke, Psychiater der Verfolgten, S. 55.

212 Venzlaff, Die psychoreaktiven Störungen.

213 Herberg/Paul (Hrsg.), Psychische Spätschäden nach politischer Verfolgung.

214 Vgl. dazu das Kapitel „Der wissenschaftliche Grabenkrieg“, in: Pross, Wiedergutmachung, S. 168184.

215 Baeyer/Häfner/Kisker, Psychiatrie der Verfolgten. 
war die Bereitschaft besonders in den 1960er Jahren gewachsen, „die Hypothek der deutschen Katastrophe auch für die Nachkriegspsychiatrie öffentlich einzugestehen “. ${ }^{216}$

Konservative Kreise der deutschen Wissenschaft weigerten sich aber weiterhin, die sorgfältigen Analysen über die Krankheitsbilder der Überlebenden anzuerkennen oder gar selbst entsprechende Untersuchungen anzustellen. Bestärkt durch die deutsche Rechtsprechung, nach der es ,auf Ansichten medizinischer Außenseiter oder spekulative Betrachtungen nicht ankomme, sondern nur auf gesicherte wissenschaftliche Erkenntnisse, wie z. B. in Lehrbüchern oder Standardwerken der Medizin“, 217 vertraten zahlreiche Ärzte des „alten Schlags“ unbeirrt ihre wissenschaftlich bereits widerlegten Thesen. Denn „die groBen Lehrbücher der , herrschenden` Lehre wurden von Männern geschrieben, denen nicht einmal die Worte KZ, Gestapo, Vernichtungslager, Rassenverfolgung, Muselmann-Stadium, Entwurzelungsdepression, Vergasung bekannt waren - die Glücklichen“, kritisierte Niederland die eigene Zunft in der Fachliteratur. ${ }^{218}$

Streitfragen, die in den 1950er und 1960er Jahren durch die Begutachtungen aufgeworfen wurden, ob etwa eine Schädigung konstitutionell bedingt oder die Folge einer erlittenen Extrembelastung sei, verschärften die Position der Reaktionäre. Die verzerrte Sichtweise, dass psychische Leiden nur auf die „eigene Schwäche“, nicht aber auf äußere Einflüsse zurückzuführen seien, hat sicherlich - denkt man an den Wertebegriff der „Mannhaftigkeit“ - historische Hintergründe. Für ein ruhiges gesellschaftliches Leben, gerade aber für den konzentrierten Wiederaufbau in den Nachkriegsjahren, mag eine solche Sichtweise von Vorteil gewesen sein - für die psychische Situation des Einzelnen jedoch nur sehr bedingt.

Brisant wurde diese Thematik nicht zuletzt im Kontext der Entschädigungsverfahren, in denen sich Überlebende des Holocaust aus heutiger Sicht unzumutbare Fragen über ihre möglicherweise anlagebedingte, „prämorbide“ Störung gefallen lassen mussten, die an den psychischen Schwierigkeiten mehr schuld sein sollte als die schrecklichen Verfolgungserlebnisse. Die damals gängige Gutachterpraxis in Wiedergutmachungsverfahren veranlasste den amerikanischen Psychoanalytiker Kurt Eissler in einem berühmt gewordenen Artikel aus dem Jahr 1963 zu der bitteren Frage: „Die Ermordung von wievieler seiner Kinder muss ein Mensch symptomfrei ertragen können, um eine normale Konstitution zu haben? "219

Ein Jahr nach dem Erscheinen dieser Publikation wies Alexander Mitscherlich als Leiter der Psychosomatischen Universitätsklinik Heidelberg das Auswärtige Amt darauf hin, dass „eine große Zahl von deutschen medizinischen Gutachtern Schwierigkeiten [hat], sich in die besondere Situation eines durch rassische oder politische Verfolgung geschädigten Menschen zu versetzen“, und empfahl, den mit den Verfahren betrauten Personen den Artikel von Kurt Eissler zugänglich zu machen. ${ }^{220}$ Das von diesem Vorschlag in Kenntnis

216 So der Historiker Franz Werner Kersting auf der Tagung „Psychiatriereform als Gesellschaftsreform“, die am 20. und 21.9.2001 in Münster vom Westfälischen Institut für Regionalgcschichte des Landschaftsverbands Westfalen-Lippe veranstaltet wurde. An ihr nahmen Historiker und Psychiater sowie Vertreter aus Gesundheitsverwaltung, Politik und psychiatrischen Fachverbänden teil. Siehe auch Kersting (Hrsg.), Psychiatriereform als Gesellschaftsreform.

217 Ausführungen Walter Brunns und Richard Hebenstreits zu BEG-SchlG Art. IV, diskutiert von Maier, Entschädigungsansprüche wegen Schadens an Körper oder Gesundheit nach dem BEG-SchlussGesetz, in: RzW 4 (1966), S. 153.

218 Niederland, Psychische Spätschäden, S.893.

219 Eissler, Ermordung.

${ }^{220}$ Prof. Mitscherlich an die Kulturabteilung des AA vom 27. 1. 1964, PA/AA, B 81/323. 
gesetzte Bundesfinanzministerium hielt den Aufsatz jedoch in keiner Weise „zu einer weiteren Verbreitung“ für geeignet, nicht zuletzt weil „hierfür auch keine geeigneten Mittel zur Verfügung“ ständen. Des Weiteren wurde in diesem Schreiben an das Auswärtige Amt argumentiert: „Viele Vorstellungen [Eisslers] sind dagegen abwegig und irreführend. [...] Manche Gedankengänge sind aus europäischer Sicht überhaupt nicht verständlich. Sie entstehen vermutlich aus der amerikanischen Auffassung und Erfahrung über die Belastbarkeit eines Amerikaners. “221

Tatsächlich führte die Verwendung von - in der Bundesrepublik anders interpretierten oder gänzlich unbekannten - wissenschaftlichen Fachbegriffen in der Begutachtung zu Problemen. Ausdrücke wie depressive reaction oder hysterical reaction konnten zur Ablehnung eines Antrags führen, weil sie im Deutschen mit endogener Depression und Hysterie übersetzt und damit als anlagebedingt klassifiziert wurden. In vielen Fällen hätten die Entscheidungen daher mit Rücksicht auf die Weiterentwicklung der medizinischen Wissenschaft überprüft werden müssen. In der Beurteilung der Auswirkungen extremer Verfolgung auf die körperliche und seelische Unversehrtheit des Verfolgten zeigte sich erst im Laufe der Jahre, dass die angewandten medizinischen Grundlagen unzureichend und zum Teil falsch waren. ${ }^{222}$ So kam auch die kritische Äußerung von William G. Niederland, wonach an den meisten Opfern, die die Verfolgung überlebt hatten, „Seelenmord“ verübt worden sei, leider zu spät, um in der deutschen Praxis der Gutachter und Gerichte ausreichend Beachtung zu finden. ${ }^{223}$

Die deutsche psychiatrische Wissenschaft musste erst erkennen, dass gerade auf dem Gebiet der Trauma-Forschung ein enormer Rückstand gegenüber den angelsächsischen Ländern bestand, der nicht zuletzt anhand der Untersuchung von NS-Verfolgten sowie deren Nachkommen - für die Wiedergutmachung in vielen Fällen leider zu spät - aufgeholt werden konnte. ${ }^{224}$ So räumt die neuere Forschung auf dem Gebiet der "Child-Survivor" mit dem Vorurteil auf, dass etwa Kleinkinder zu jung gewesen seien, um das damalige Geschehen zu begreifen, im Sinne einer frühkindlichen Amnesie keine Erinnerung mehr daran hätten und deshalb auch keinerlei psychische Spätfolgen davontrügen. ${ }^{225}$ Als erwiesen gilt auch, dass gerade während bestimmter Lebensabschnitte - etwa der Pubertät - eine größere Verletzbarkeit der menschlichen Psyche anzunehmen ist. Besonders problematisch sei es, „wenn die Verfolgung als integraler Bestandteil in die noch nicht abgeschlossene Entwicklung eingreift“, stellt die Psychoanalytikerin Karin Gäßler in einer Studie fest. ${ }^{226}$

Unter den überlebenden Opfern von Menschenversuchen sind in diesem Zusammenhang insbesondere die „Mengele-Zwillinge“ zu nennen, da es sich bei ihnen vorwiegend um Kinder und Jugendliche handelte, die zu den Experimenten herangezogen wurden. Ein Wiedergutmachungsanspruch aufgrund des Kabinettsbeschlusses wurde in diesen Fällen jedoch bis ins Jahr 1987 von den zuständigen deutschen Stellen verneint, da es sich nach

221 BMF an AA, 16.6. 1964, PA/AA, B 81/323.

222 Zit. nach Focke, Psychiater der Verfolgten, S. 97.

223 Niederland, Folgen der Verfolgung.

224 So zum Beispiel Stoffels (Hrsg.), Schicksale der Verfolgten; Kersting (Hrsg.), Psychiatriereform als Gesellschaftsreform; 2001 gründeten der Psychologe Jürgen Müller-Hohagen und seine Frau das Dachau Institut Psychologie \& Pädagogik, um im internationalen Austausch über die seelischen Auswirkungen von Gewalt $u$. a. bei NS-Verfolgten und ihren Nachkommen zu forschen; vgl. auch MüllerHohagen, Verleugnet, verdrängt, verschwiegen.

${ }^{225}$ Kestenberg, Kinder von Überlebenden, S. 115; außerdem Lempp, Langzeitwirkungen.

226 Gäßler, Wunden, die nicht vergehen, S. 55. 
deren Auffassung nicht um „gesundheitsschädigende Ereignisse“ gehandelt habe. ${ }^{227}$ Während sich die medizinische Lehrmeinung wandelte, war die vollzogene Rechtsprechung im Fall der überlebenden Opfer von Menschenversuchen irreversibel. Einen Anspruch auf Überprüfung des Antrags aus medizinischen Gründen lehnte das Bundesfinanzministerium für diese Opfergruppe kategorisch $a b .{ }^{228}$

Neben diesen offensichtlichen, eventuell vermeidbaren Unzulänglichkeiten in der Entschädigungspraxis bei Körper- und Gesundheitsschäden ergaben sich eine ganze Reihe von Schwierigkeiten aus der komplizierten Begutachtungssituation. In diagnostischer wie therapeutischer Hinsicht war der Umgang mit ehemals Verfolgten mit gravierenden Problemen verknüpft, da das Verhältnis zwischen Gutachter und Antragsteller angespannt war. Unter welchen Voraussetzungen und mit welchen Konsequenzen fand diese Begegnung statt?

Während vom Antragsteller eine vertrauensvolle Erschließung seiner Verfolgungs- und Krankheitsgeschichte erwartet wurde, übertrug der Geschädigte nicht selten Angst und Aggression auf den deutschen Arzt, der gleichzeitig Vertreter einer Instanz war, die in der Rechtsnachfolge des Unrechtsstaats stand. Dass die Verfolgten unter diesen Umständen Ressentiments gegen deutsche Gutachter hegten, ist naheliegend - im Fall der überlebenden Opfer von Menschenversuchen angesichts der Lagererlebnisse mit deutschen Ärzten jedoch geradezu unvermeidlich. Dass man sich in den deutschen Auslandsvertretungen dieser Problematik durchaus bewusst war, beweist ein Schreiben der Botschaft in Brüssel an das Auswärtige Amt: „Erfahrungsgemäß sind die früheren KZ-Häftlinge, vor allem aber die Opfer der Menschenversuche, misstrauisch, sehr empfindlich und schwer zugänglich. Aus leicht verständlichen psychologischen Gründen wird diese Haltung gegenüber deutschen Dienststellen noch betonter."229

Viele Betroffene empfanden es geradezu als Verhöhnung ihres Schicksals, wenn sie während des Wiedergutmachungsverfahrens ausgerechnet deutsche medizinische Sachverständige konsultieren mussten. Das tief verwurzelte Misstrauen gegenüber einer Person, die all das symbolisierte, was mit den Tätern assoziiert wurde, führte unweigerlich zu einer belastenden Begutachtungssituation, in der sich der Betroffene nicht frei genug fühlte, alle Veränderungen seiner Persönlichkeit während und nach der Verfolgung ungehemmt darzulegen.

Aber auch für die ärıtlichen Sachverständigen war die Situation aufgrund der Übertragungspotenziale außerordentlich schwierig, so dass selbst motivierte Gutachter davor zurückschreckten, sich intensiv auf eine Exploration des Verfolgungsgeschehens einzulassen. So bestand nicht nur die Problematik für den Gutachter, mit dem Täter assoziiert zu werden, sondern auch die Gefahr einer sogenannten Gegenübertragung auf den Antragsteller aufgrund möglicherweise unbewusster Verhaftungen des Gutachters in eine belastete Vergangenheit. ${ }^{230}$

Des Weiteren muss man davon ausgehen, dass Verdrängungs- und Abwehrreaktionen gegenüber dem Schrecklichen, von dem die Überlebenden berichteten, nicht nur im sozialen Umfeld der Betroffenen, sondern auch bei den Sachverständigen zum Tragen kamen.

227 Mit der Begründung, dass diese Versuche in Nürnberg nicht zur Verhandlung gekommen seien und es sich ferner nur um Blutentnahmen gehandelt habe, wurden die Entschädigungsansprüche der Opfer von Zwillingsversuchen abgelehnt, vgl. BMF an die zuständige Vertrauensärztin in Israel, 5.2.1954, BA, B 126/12553.

228 BMI an BMF, 23.9. 1954, BA, B 126/12554.

229 Botschaft Brüssel an AA, 19.11. 1951, PA/AA, B 81/147.

${ }^{230}$ Zur Problematik der Übertragung bei der psychotherapeutischen Arbeit mit Verfolgungsopfern siehe De Wind, Begegnung mit dem Tod. 
„Die Bereitschaft, dem Überlebenden zuzuhören, ist [...] sehr gering. Es ist, als trügen die Opfer einen Makel an sich, der zerstörerisch ist, eine Botschaft des Todes, vor der man flieht, wenn man das eigene Heil sucht", beschreibt der Psychotherapeut Hans Stoffels dieses Phänomen. ${ }^{231}$ In einem Gespräch mit dem Spiegel-Redakteur Martin Doerry im November 2006 bestätigte die Holocaust-Überlebende Anita Lasker-Wallfisch, dass „über Jahrzehnte niemand zuhören wollte", alle hätten geschwiegen und keiner gefragt. ${ }^{232}$

Es zeigte sich, dass auch professionelle „Helfer“ wie Ärzte, Psychiater oder Psychotherapeuten lange Zeit kaum Verständnis für die bedrückenden Botschaften der Überlebenden aufbrachten und diese nicht in ihre Vorstellungswelt integrieren konnten. Dem Gegenüber wurde diese innere Haltung zwar nicht direkt mitgeteilt, jedoch nonverbal - in den meisten Fällen sicherlich unbewusst - kommuniziert. Der Erzähler wiederum nahm diese Reaktionen unbewusst wahr, sah sich mit dem impliziten Vorwurf der „Lüge“ konfrontiert und reagierte mit innerem Rückzug und Schweigen. ${ }^{233}$

$\mathrm{Da}$ in der Begutachtungspraxis die Gesundheitsschäden vorzugsweise als Störungen rein körperlicher Natur klassifiziert wurden, konnte man bei Antragstellern häufig das Phänomen des „Zwangs zur Symptomanpassung“ finden. ${ }^{234}$ Hierunter ist die Tatsache zu verstehen, dass der Geschädigte seine Beschwerden im Allgemeinen unter dem Aspekt schilderte, der ihm - in seinem laienhaften Verständnis - hinsichtlich eines Entschädigungsanspruchs erfolgversprechend erschien. Da das psychische Syndrom in der Begutachtung lange Zeit keine Rolle spielte, stellten sich die Verfolgten vielfach auf das somatische Konzept ein, um dem ärztlichen Vorurteil einer „Entschädigungsneurose“ nicht in die Hand zu spielen und eine ungünstige Beurteilung zu vermeiden. ${ }^{235}$ Nicht zuletzt wurden die Symptome sowohl durch die Vorstellungen des Gutachters als auch durch die Selbstinterpretation des Untersuchten geformt, was zu erheblichen Verzerrungen führte und eine vollständige und adäquate Erfassung der verfolgungsbedingten Spätschäden wenn nicht verhinderte, so doch erheblich verzögerte.

Die Angst der Entschädigungsbehörden vor unberechtigten Ansprüchen war in den meisten Fällen unbegründet, da die Verfolgten erfahrungsgemäß bei ihren Schilderungen nicht übertrieben, sondern oft sogar das Gegenteil der Fall war. Bei den Betroffenen setzte ein Verdrängungsmechanismus ein, der sich in einem eingeschränkten Verbalisierungsvermögen äußerte. Zu diesem Ergebnis kam der Psychiater William G. Niederland. ${ }^{236}$ Konflikte und traumatische Erfahrungen wurden aus dem Bewussten in die Schichten des Unbewussten verlagert, um den Alltag bewältigen zu können. Dass „eine große Anzahl der Rechtsuchenden nicht die Fähigkeit hat, innere Zustände zu verbalisieren“, ist gutachterlich jedoch bei weitem nicht immer richtig interpretiert worden. ${ }^{237}$ Vielmehr wurden viele

231 Schmitt/Stoffels, Wiederkehr des Verfolgungstraumas, S. 72.

232 Anlässlich der Präsentation des Buches „,Nirgendwo und Überall zu Haus‘. Gespräche mit Überlebenden des Holocaust" sprach der Autor Martin Doerry am 19.11.2006 mit Anita Lasker-Wallfisch, vgl. Doerry, „Nirgendwo und Überall zu Haus“.

${ }^{233}$ In der Literatur wird dieses Phänomen als „Verschwörung des Schweigens“ bezeichnet, vgl. Eitinger, Lebenswege, S. 12.

${ }^{234}$ Matussek, Konzentrationslagerhaft, S. 38.

235 Aus einer von Matussek angestellten Analyse geht deutlich hervor, dass bei organisch begründbaren Erkrankungen mit Abstand höhere Berentungsvorschläge gemacht wurden als bei erlebnisreaktiven seelischen Störungen, vgl. Matussek, Konzentrationslagerhaft, S. 72-74.

236 Niederland, Folgen der Verfolgung, S. 230.

237 Eissler, Ermordung, S. 255. 
Antragsteller oftmals aufgrund ihrer mangelnden Sprachkenntnisse als „unterdurchschnittlich begabt" beurteilt. So spricht aus einigen gutachterlichen Ablehnungsgründen eine „traditionelle Denkart“, der jegliches Mitgefühl und Verständnis für das individuelle Schicksal fehlte.

Auch die Aufklärung der Verfolgungssituation bereitete gravierende Probleme, da nicht selten Erinnerungsschwierigkeiten affektiver Art den Verfolgten vor der Reaktualisierung der leidvollen Ereignisse, den sogenannten flash-backs, bewahrten. Inwieweit überhaupt vom Antragsteller erwartet werden konnte, den eigenen Zustand zu reflektieren, sich seelischer Leiden bewusst zu werden und diese gegenüber dem Sachverständigen zu artikulieren, wurde von den zuständigen Behörden nicht thematisiert.

$\mathrm{Zu}$ Recht wies Niederland in diesem Zusammenhang auf die erheblichen Belastungen hin, die Verfolgte bei den Untersuchungen, die sich oft auch noch wiederholten, ertragen mussten. Über das Erlittene zu reden, war für die Überlebenden aufgrund des Übermaßes an Leiden und Entwürdigungen oft schwer, wenn nicht unmöglich. Die Wiederbelebung des Verfolgungstraumas durch Verfahren und Begutachtung konnte einen "posttraumatischen Verfolgungsdruck“ auslösen, der die Leiden der Betroffenen unter Umständen noch verstärkte. Wenn, wie in einigen Fällen geschehen, der Streit über medizinische Grundsatzfragen auf dem Rücken der Verfolgten ausgetragen wurde, bedeutete dies für die Antragsteller oft einen jahrelangen Weg von Gerichtsinstanz zu Gerichtsinstanz und von Arzt zu Arzt.

„Der Patient müßte eigentlich eine Entschädigung erhalten für die Aufregungen und Erniedrigungen, die er im Zuge des Wiedergutmachungsverfahrens erlitten hat", kritisierte der Psychoanalytiker Kurt Eissler angesichts solcher qualvoller Prozeduren, die das ehemals geschehene Unrecht in den Augen der Betroffenen nicht nur fortsetzten, sondern sogar unter Umständen noch verschärften. ${ }^{238}$ So schrieb ein in Kanada lebender Antragsteller, der nach eigenen Angaben im Konzentrationslager Dachau infolge mehrerer Injektionen mit einer unbekannten Flüssigkeit Typhusfieber bekommen hatte und später Kälteversuchen ausgesetzt worden war, dem Deutschen Generalkonsulat in Montreal enttäuscht: „Il me semblait qu'on a voulu donner compensation matérielle et morale pour le tort qu'on m'a fait, pour les cruautés morales et physiques érigées en système. L'idée a été généreuse, mais l'exécution. "239 Bei den überlebenden Opfern von Menschenversuchen waren Resignation und Verbitterung über die administrative Praxis im Rahmen der Durchführung des Kabinettsbeschlusses von 1951 kein Einzelfall. ${ }^{240}$

238 Eissler, Ermordung, S. 279.

239 Aus dem Brief eines Antragstellers, zit. nach einem Schreiben des Deutschen Generalkonsulats in Montreal an AA vom 12.4.1953, PA/AA, B 81/147.

${ }^{240}$ Das jedenfalls stellte das Deutsche Generalkonsulat in Montreal fest, das mit einer ganzen Reihe derartiger Fälle befasst war, vgl. Generalkonsulat Montreal an AA, 12.4. 1953, PA/AA, B 81/147. 